\title{
Disruption of Epithalamic Left-Right Asymmetry Increases Anxiety in Zebrafish
}

\author{
Lucilla Facchin, ${ }^{\star}$ Erik R. Duboué, ${ }^{\star}$ and Marnie E. Halpern \\ Carnegie Institution for Science, Department of Embryology, Baltimore, Maryland 21218
}

Differences between the left and right sides of the brain are found throughout the animal kingdom, but the consequences of altered neural asymmetry are not well understood. In the zebrafish epithalamus, the parapineal is located on the left side of the brain where it influences development of the adjacent dorsal habenular $(\mathrm{dHb})$ nucleus, causing the left and right $\mathrm{dHb}$ to differ in their organization, gene expression, and connectivity. Left-right (L-R) reversal of parapineal position and $\mathrm{dHb}$ asymmetry occurs spontaneously in a small percentage of the population, whereas the $\mathrm{dHb}$ develop symmetrically following experimental ablation of the parapineal. The habenular region was previously implicated in modulating fear in both mice and zebrafish, but the relevance of its L-R asymmetry is unclear. We now demonstrate that disrupting directionality of the zebrafish epithalamus causes reduced exploratory behavior and increased cortisol levels, indicative of enhanced anxiety. Accordingly, exposure to buspirone, an anxiolytic agent, significantly suppresses atypical behavior. Axonal projections from the parapineal to the $\mathrm{dHb}$ are more variable when it is located on the right side of the brain, revealing that $\mathrm{L}-\mathrm{R}$ reversals do not necessarily represent a neuroanatomical mirror image. The results highlight the importance of directional asymmetry of the epithalamus in the regulation of stress responses in zebrafish.

Key words: habenula; interpeduncular nucleus; stress; cortisol; buspirone

\section{Significance Statement}

The asymmetric epithalamus of zebrafish has emerged as a valuable model to explore the formation and function of left-right differences in the brain. To probe the relationship between brain laterality and behavior, we examined the effects of left-right reversal of epithalamic asymmetry or symmetric development on behavior. In both cases, zebrafish showed increased measures of fear/anxiety, including reduced exploratory behavior and delayed exit from a confined space. Adults with reversed L-R asymmetry also have elevated cortisol levels relative to controls. The results reveal the importance of directional asymmetry of the dorsal diencephalon in the modulation of anxiety.

\section{Introduction}

Neuroanatomical and molecular differences between the left and right sides of the brain have been uncovered in both vertebrate and invertebrate species. Bilateral chemosensory neurons mediating olfaction and taste in Caenorhabditis elegans differ in their size, gene expression, and signaling properties, and show biases in their response to the same cues (Poole and

Received July 7, 2015; revised Sept. 22, 2015; accepted 0ct. 14, 2015.

Author contributions: L.F., E.R.D., and M.E.H. designed research; L.F. and E.R.D. performed research; L.F., E.R.D., and M.E.H. analyzed data; L.F., E.R.D., and M.E.H. wrote the paper.

This work was supported by National Institute of Child Health and Human Development 5R01HD042215-10. We thank Mahmud Siddiqi for help with MATLAB programming and image analysis; Rafael Villagaray for video editing; Bill Kupiec for assistance with figures; Allen Strause for constructing behavioral apparatuses; and Tagide deCarvalho and Samer Hatter for helpful comments.

The authors declare no competing financial interests.

*L.F. and E.R.D. contributed equally to this work.

Correspondence should be addressed to Dr. Marnie E. Halpern, Carnegie Institution for Science, Department of Embryology, 3520 San Martin Drive, Baltimore, MD 21218. E-mail: halpern@ciwemb.edu.

DOI:10.1523/JNEUROSCI.2593-15.2015

Copyright $\odot 2015$ the authors $\quad 0270-6474 / 15 / 3515847-13 \$ 15.00 / 0$
Hobert, 2006; Suzuki et al., 2008; Lesch et al., 2009; Cochella et al., 2014). In birds, left-right (L-R) asymmetry in the tectofugal and thalamofugal pathways is associated with lateralization of visual behaviors (Deng and Rogers, 1997; Güntürkün et al., 1998; Rogers, 2008; Valencia-Alfonso et al., 2009; Manns and Römling, 2012). The right basolateral amygdala of rats shows increased neural activation and norepinephrine release in the absence of an expected reward (Young and Williams, 2010, 2013). However, outside of a few examples, little is known about the influence of L-R differences in neuronal organization and activity on behavior.

The zebrafish epithalamus has become a valuable model to study the relationship between L-R asymmetry and behavior (Barth et al., 2005; Facchin et al., 2009a,b). The bilaterally paired, dorsal habenular $(\mathrm{dHb})$ nuclei show prominent differences in their size, timing of cell proliferation, subnuclear organization, neuropil density, connectivity, and gene expression (Concha and Wilson, 2001; Concha et al., 2003; Gamse et al., 2003, 2005; Aizawa et al., 2005, 2007; Kuan et al., 2007b). The pineal complex, 

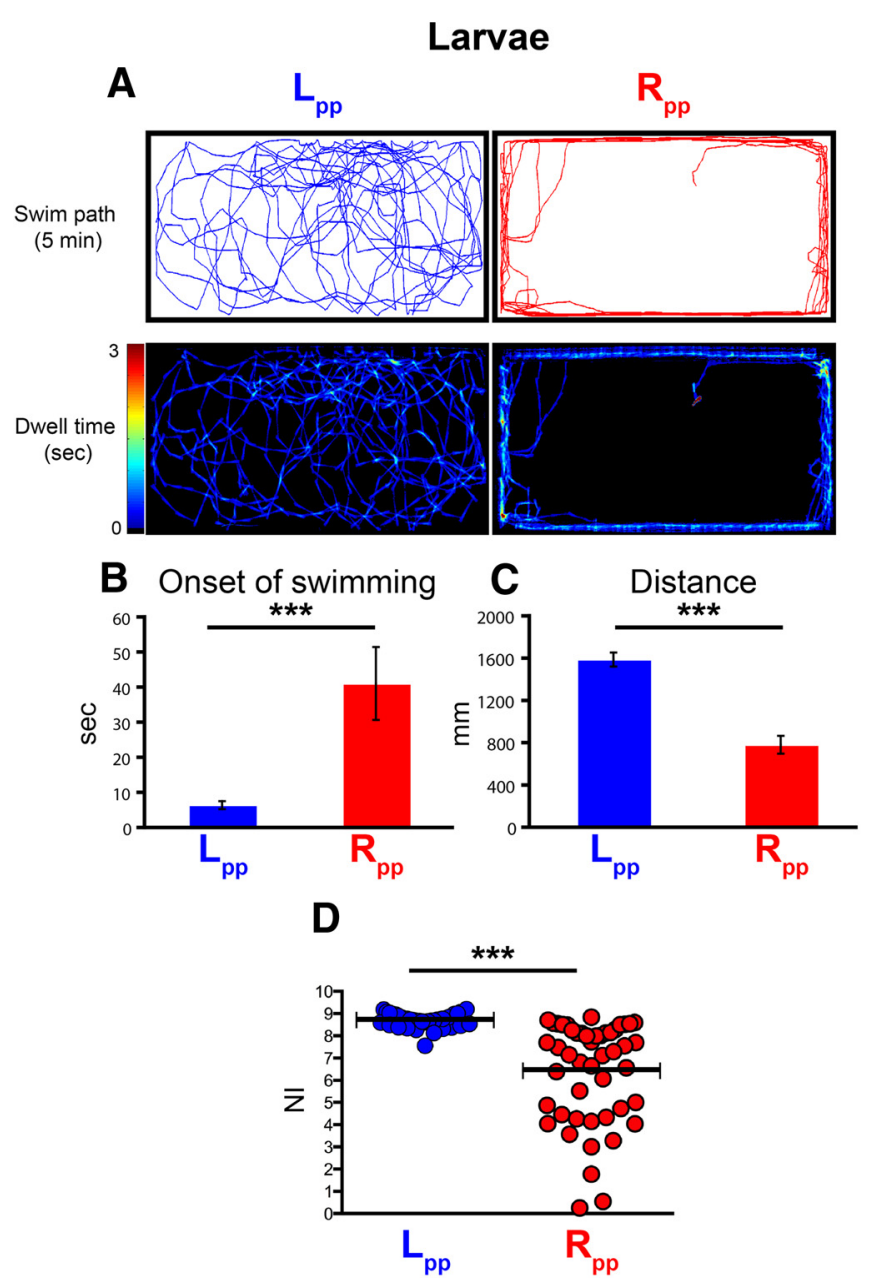
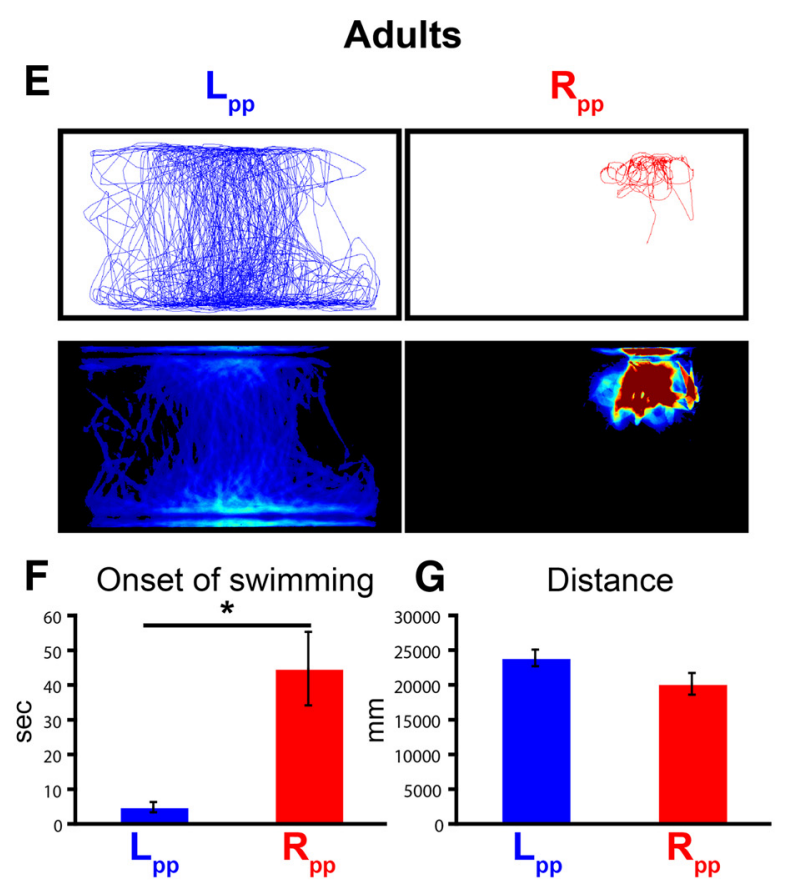

H

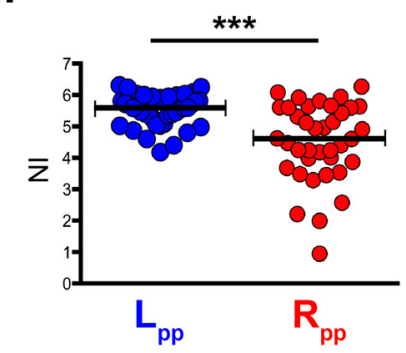

Figure 1. Reversal of epithalamic asymmetry alters navigational behavior in a visual cue-dependent manner. $\boldsymbol{A}, \boldsymbol{E}$, Representative swim path and corresponding accumulated dwell time in seconds over a 5 min recording period for individual $L_{p p}$ (blue) and $R_{p p}\left(\right.$ red) $(\boldsymbol{A})$ larval and $(\boldsymbol{E})$ adult zebrafish in the mirror assay. $\boldsymbol{B}, \boldsymbol{F}, \boldsymbol{M}_{\text {ean }} \pm \mathrm{SE}$ of the elapsed time before $\mathrm{L}_{\mathrm{pp}}$ and $\mathrm{R}_{\mathrm{pp}}(\boldsymbol{B})$ larvae or $(\boldsymbol{F})$ adults swam a distance equivalent to twice their body length. $\mathrm{R}_{\mathrm{pp}}$ larvae (Mann-Whitney $U=507, p<0.001$ ) and adults (Mann-Whitney $U=497, p=0.013$ ) show a significant delay in the onset of swimming. $\mathbf{C}, \mathbf{G}$, Mean \pm SE of the total distance in millimeters $L_{p p}$ and $R_{p p}(\boldsymbol{C})$ larvae or $(\boldsymbol{G})$ adults traveled over a 5 min period. The total distance was calculated by tracking the cumulative movements of an individual larva or adult fish frame by frame. The larvae showed a significant difference in the total distance they swam (Mann-Whitney $U=286, p<0.001$ ), but the adults did not (Mann-Whitney $U=583, p=0.108$ ). $\boldsymbol{D}, \boldsymbol{H}$, The $\mathrm{NI}$ of $(\boldsymbol{D})$ larval and $(\boldsymbol{H})$ adult zebrafish represents the distribution of an individual's position in the tank over time. Circles represent single test subjects. Bar represents median value. Differences between the NI distributions were highly significant for $L_{p p}$ and $R_{p p}$ larvae (Mann-Whitney $\left.U=139, p<0.001\right)$ and adults (Mann-Whitney $U=404, p<0.001$ ). ${ }^{* * *} p<0.001$. ${ }^{*} p<0.05$.

situated between them, includes the pineal and parapineal organs. In the majority of embryos, the parapineal develops to the left of the presumptive pineal and, in adults, it remains on the left at the base of the pineal stalk. The direction of epithalamic asymmetry is spontaneously reversed in $2 \%-5 \%$ of zebrafish (Concha et al., 2000; Liang et al., 2000) but can also be manipulated by disruption of the nodal signaling pathway, increasing the proportion to nearly 50\% (Gamse et al., 2003; Facchin et al., 2009b).

The functional relevance of epithalamic asymmetry is unresolved. L-R reversed larvae show a corresponding reversal in the directionality of some, but not all, behavioral responses (Barth et al., 2005). In a commonly used test for L-R bias in eye use, self-viewing in a tank with mirrors ("mirror test"; Sovrano et al., 1999; Sovrano and Andrew, 2006), we found that $\mathrm{L}-\mathrm{R}$ reversal of epithalamic asymmetry did not result in a statistically significant difference in eye use at the populational level (Facchin et al., 2009b). The larvae moved and responded to stimuli normally but were delayed in their onset of swimming and explored less area of the assay tank.

We now show that reduced exploratory behavior persists in adult zebrafish and is due, in part, to visual stimuli provided by the mirrors. In addition, adults with L-R reversed brain asymmetry spend more time in the bottom half of an unfamiliar tank. In response to stress, whole-body cortisol levels are also significantly elevated compared to controls. Abnormal behavior, however, is suppressed following treatment with the anxiolytic drug buspirone. The altered behavioral and physiological responses are indicative of enhanced anxiety, demonstrating that reversal of L-R asymmetry is sufficient to modify neuronal function.

\section{Materials and Methods}

Fish. Fish strains used in this study were wild-type AB (Walker, 1999) and the $T g\left(f_{0} x d 3: G F P\right)^{\mathrm{fkg} 17}$ (Gilmour et al., 2002) line. $\mathrm{AB}$ or $T g\left(f_{0} x d 3\right.$ : $G F P)^{\mathrm{fkg} 17}$ homozygotes were bred and resultant embryos maintained at 
A

\section{Mirrors}

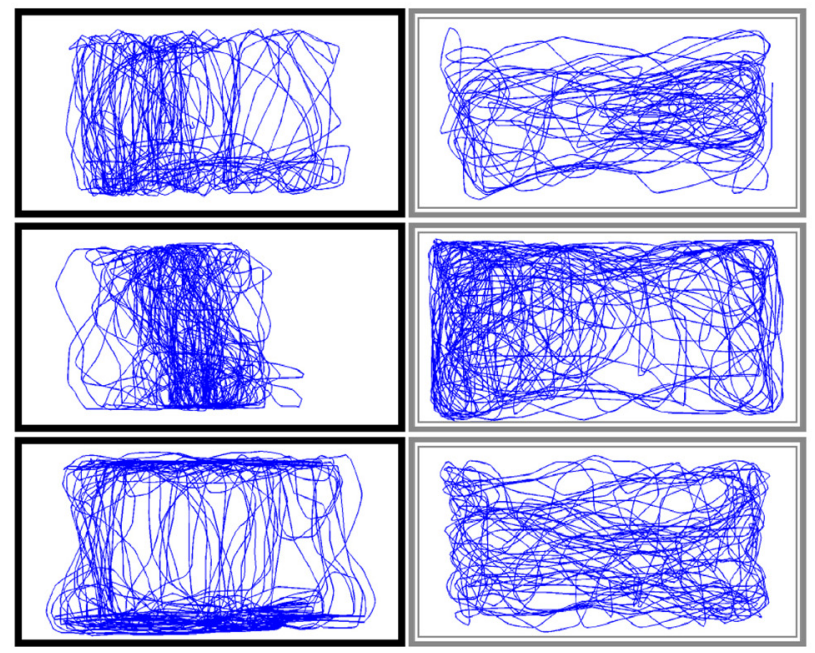

Mirrors

C

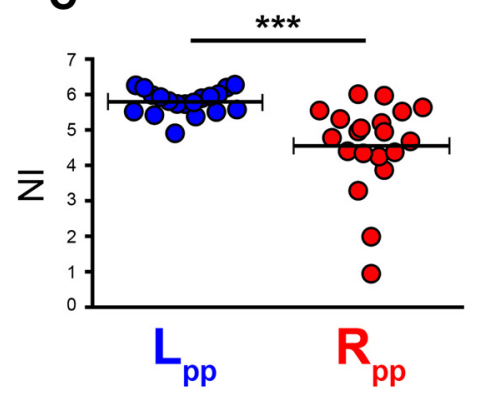

B
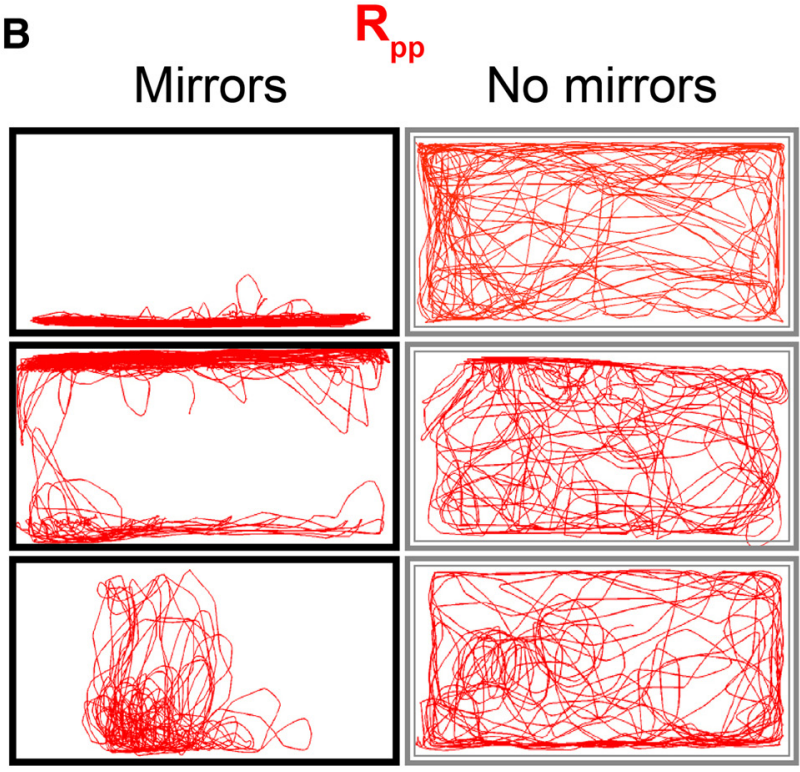

No mirrors

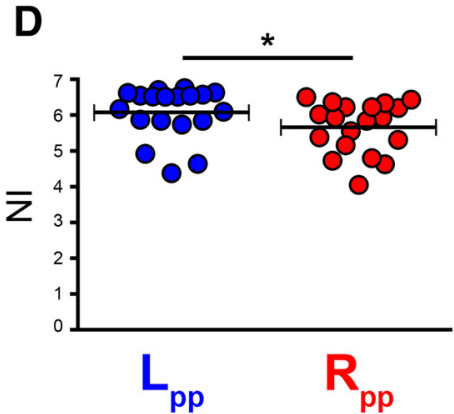

Figure 2. Impact of visual cues on navigational behavior. $\boldsymbol{A}, \boldsymbol{B}$, Representative swim paths over a 5 min period of the same individual $(\boldsymbol{A}) \mathrm{L}_{\mathrm{pp}}$ or $(\boldsymbol{B}) \mathrm{R}_{\mathrm{pp}}$ adult fish assayed with and without mirrors. $\boldsymbol{C}, \boldsymbol{D}$, Distribution and median value (capped line) of the NI for all $\mathrm{L}_{\mathrm{pp}}$ and $\mathrm{R}_{\mathrm{pp}}$ adults tested $(\boldsymbol{C})$ with and $(\boldsymbol{D})$ without mirrors. On average, $\mathrm{R}_{\mathrm{pp}}$ adults had a significantly lower Nl in the presence of mirrors than their $\mathrm{L}_{\mathrm{pp}}$ siblings (Mann-Whitney $U=41, p<0.001$ ), but the two groups behaved more similarly when the mirrors were removed (Mann-Whitney $\left.U=103, p=0.024\right) .{ }^{* * *} p<$ 0.001. ${ }^{*} p<0.05$.

$27^{\circ} \mathrm{C}$. In the latter, parapineal position was scored at $3 \mathrm{~d}$ post fertilization (dpf). All behavioral experiments were performed with the same system water used to maintain zebrafish in the aquatics facility.

For the novel tank diving test and cortisol measures, $\operatorname{Tg}($ foxd 3 : $G F P)^{\mathrm{fkg} 17}$ zebrafish embryos were injected at the 1 cell stage with 5-10 ng of a translation blocking morpholino for the southpaw gene (Long et al., 2003). Larvae were sorted at $3 \mathrm{dpf}$ based on the position of the parapineal and raised to either $8 \mathrm{dpf}$ or adulthood. The Institutional Animal Care and Use Committee of the Carnegie Institution Department of Embryology approved all protocols.

Behavioral assays. Behavioral tests were performed on $8 \mathrm{dpf}$ larvae and 12- to 14-week-old adults. All individuals were assayed between 1:00 and 6:00 P.M. Differences between the responses of males and females were not detected in parapineal positioned on the left side of the brain $\left(\mathrm{L}_{\mathrm{pp}}\right)$ or parapineal positioned on the right side of the brain $\left(\mathrm{R}_{\mathrm{pp}}\right)$ adults.

Mirror test. The testing apparatus was a rectangular tank $(10 \times 4 \times$ $4 \mathrm{~cm}$ for larvae and $36 \times 18 \times 12 \mathrm{~cm}$ for adults) with mirrors as the two long walls and opaque, white Plexiglas for the short walls. When the test was conducted without mirrors, all walls were white Plexiglas. Tanks were filled with $27^{\circ} \mathrm{C}$ water to a depth of $3 \mathrm{~cm}$ for larvae and 11 $\mathrm{cm}$ for adult fish and evenly illuminated by two overhanging $15 \mathrm{~W}$ fluorescent lamps. $\mathrm{L}_{\mathrm{pp}}$ and $\mathrm{R}_{\mathrm{pp}}$ larvae or adults were preadapted for at least $3 \mathrm{~h}$ to light of the same intensity as the experimental chamber. Individuals were gently placed in the middle of the tank and swimming behavior was recorded for $5 \mathrm{~min}$ at 30 frames/s with a Canon $\mathrm{XH}-\mathrm{A} 1 \mathrm{high}$ definition digital video camera suspended above the apparatus. When the same fish were assayed with and without mirrors, the two tests were separated by a 1 week interval. The order of the two tests was randomized and did not significantly influence behavior of $\mathrm{L}_{\mathrm{pp}}$ (Kendall's W test, $\chi_{(9,3)}^{2}=4.6, p=0.204$ ) or $\mathrm{R}_{\mathrm{pp}}$ fish (Kendall's $\mathrm{W}$ test, $\left.\chi_{(9,3)}^{2}=5.9, p=0.115\right)$. Video processing and analysis tasks were programmed in MATLAB (The MathWorks), and all recorded frames were analyzed ( 9000 frames/test). The onset of swimming was defined as the time required for a larva or adult to swim at least two body lengths away from its initial position. The total distance was calculated from the change in the fish position between each video frame.

The Navigation Index (NI) was developed to describe the swimming behavior of larvae and adults and is a measure of how widely a subject's position is distributed within the assay tank during the testing period. The total area of the tank was divided into evenly spaced subregions (bins) derived from the length of larval and adult fish. From the tracking data for each test, the probability of a subject being in each bin was calculated (number of appearances in each bin divided by the total number of tracked positions) and, on the basis of these probabilities, the Shannon Uncertainty (Shannon, 1948) for the fish's position over the duration of the test was calculated using base 2 logarithms. This value was designated as the NI with a formula of $\mathrm{NI}=-\sum_{\mathrm{i}=1}^{\mathrm{n}} \mathrm{p}_{\mathrm{i}} \log 2\left(\mathrm{p}_{\mathrm{i}}\right)$ where $\mathrm{p}_{\mathrm{i}}$ is probability of a test subject appearing in a given bin (i) during the test period, and is calculated as the number of appearances in the bin (i) divided by the total number of appearances in all bins $(\mathrm{n})$. 
A

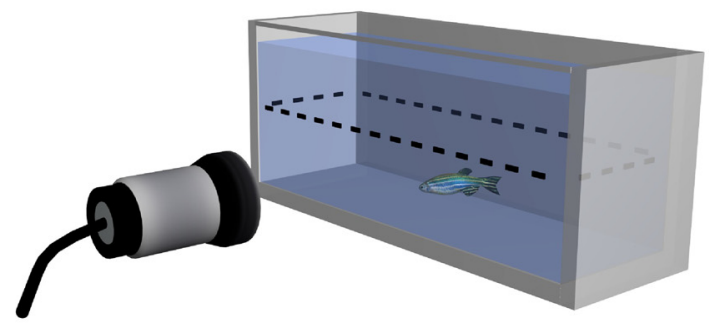

C

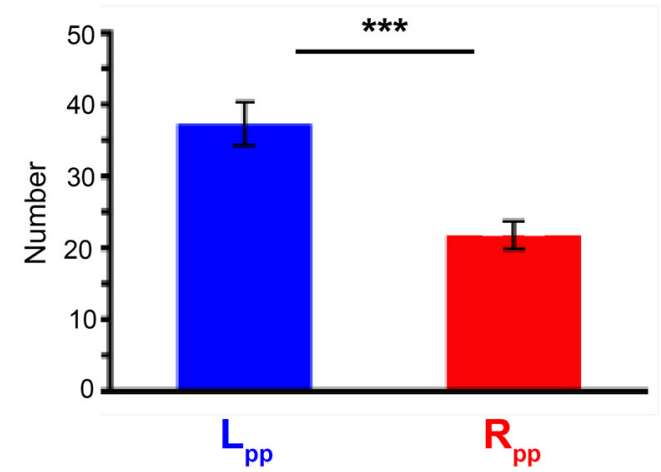

B

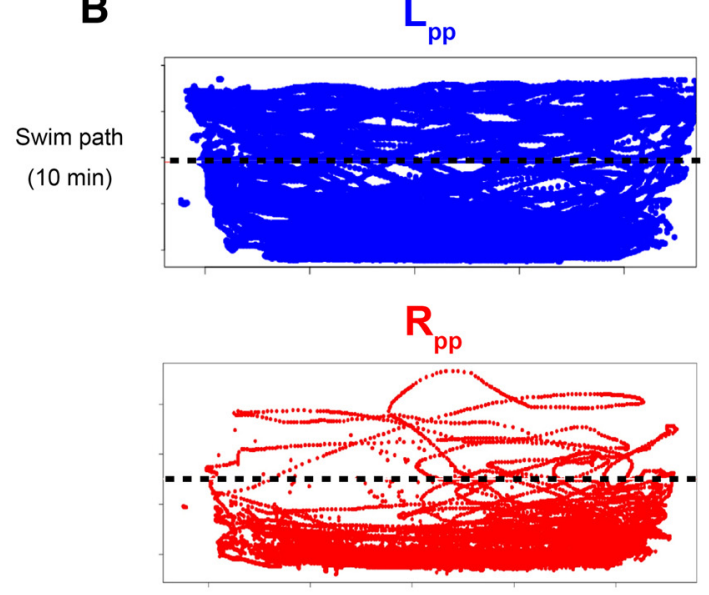

D Duration spent in top half

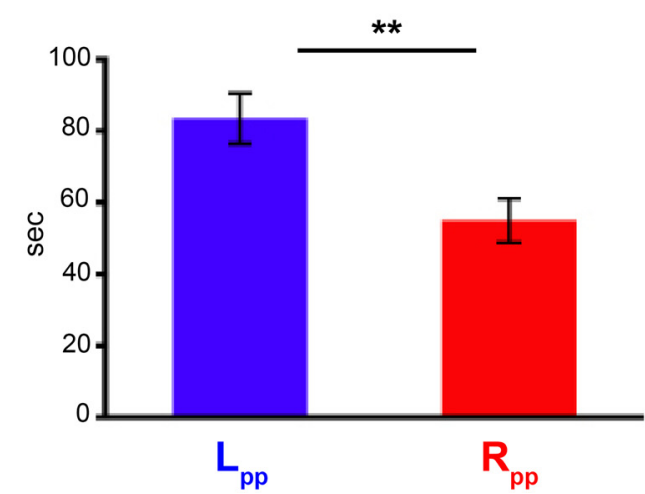

Figure 3. Adults with $\mathrm{L}-\mathrm{R}$ reversal show prolonged bottom dwelling. $\boldsymbol{A}$, Schematic of the apparatus for the novel tank diving test. $\boldsymbol{B}$, Representative tracings of $\mathrm{L}_{\mathrm{pp}}$ and $\mathrm{R}_{\mathrm{pp}}$ adults over a 10 min period. Black dashed lines indicate the top and bottom halves of the tank. The number of entries $(\boldsymbol{C})$ into the top half (Mann-Whitney $U=1063$; $\left.{ }^{* * *} p<0.001\right)$ and total duration spent there (seconds) (D) (Mann-Whitney $U=1214, p=0.002 ;{ }^{* *} p<0.01$ ) were significantly lower in $\mathrm{R}_{\mathrm{pp}}$ adults compared with $\mathrm{L}_{\mathrm{pp}}$ siblings.

The scale of the NI is logarithmic and not linear (e.g., a NI of 6 represents a positional distribution twice as broad as a NI of 5 , and four times as broad as a NI of 4). Because of differences in the size of test tanks, NI values are not directly comparable for larvae and adults.

Confined box test. The test chamber was a box $(8 \times 6.5 \times 6 \mathrm{~cm})$ with two exits $2 \mathrm{~cm}$ in diameter. The walls and bottom were opaque black Plexiglas. An opaque lid blocked both exits and excluded light from the interior of the box. The box was submerged in an illuminated (15 $\mathrm{W}$ fluorescent lamps) external tank with surrounding water maintained at $27^{\circ} \mathrm{C}$. Adults were confined within the box for $5 \mathrm{~min}$, after which the lid was removed and the exit holes opened. Behavior was recorded with a video camera suspended above the apparatus. The latency to emerge was defined as the time elapsed from the opening of the lid to the fish's first approach to either exit hole. Stall time was defined as the time the fish took to emerge from the box after reaching the exit hole.

Novel tank diving test. The testing apparatus was a rectangular tank (dimensions $13 \mathrm{~cm} \times 23 \mathrm{~cm} \times 13 \mathrm{~cm}$ ) filled with fresh $27^{\circ} \mathrm{C}$ system water to $10 \mathrm{~cm}$ high. A camera attached to a fixed focal length lens was mounted in front of the tank. After a minimum of $1 \mathrm{~h}$ acclimation, individual $T g\left(f \circ d_{3}: G F P\right)^{f k g 17}$ adults were gently placed in the test tank and their swimming activity recorded for $10 \mathrm{~min}$. All recordings were captured and analyzed using ZebraLab software (Viewpoint Life Sciences).

Cortisol measurements. Adult zebrafish (3-6 months old) were placed individually into a $0.7 \mathrm{~L}$ tank with a mesh bottom that was inserted into a closed-bottom $0.7 \mathrm{~L}$ tank. Adults were lifted out of water for $4 \mathrm{~min}$ by raising the mesh-bottom cage and then were placed back in water for recovery times ranging from 15 to $120 \mathrm{~min}$, after which they were killed by rapid freezing.
Whole-body cortisol levels were measured as previously described (Cachat et al., 2010). Single fish were homogenized in $2 \mathrm{ml}$ of ice-cold PBS using a tissue homogenizer. To extract glucocorticoids, $5 \mathrm{ml}$ of diethyl ether was added to the homogenate, the sample vortexed for 1 min and centrifuged at $4^{\circ} \mathrm{C}$ for $10 \mathrm{~min}$. The organic phase containing glucocorticoids was transferred to a glass test tube, and the diethyl ether extraction process was repeated twice. The diethyl ether was evaporated in a fume hood overnight, and residual glucocorticoids were reconstituted in $1 \mathrm{ml}$ of $1 \times \mathrm{PBS}$ overnight at $4^{\circ} \mathrm{C}$. Cortisol levels were measured using a human salivary cortisol EIA kit according to the manufacturer's protocol (Salimetrics), and the results were normalized to total protein (Bio-Rad Protein Assay).

Pharmacology. Different groups of $\mathrm{L}_{\mathrm{pp}}$ and $\mathrm{R}_{\mathrm{pp}}$ adult zebrafish were tested in each behavioral assay before and after exposure to buspirone hydrochloride (Sigma). Following baseline measurements in the absence of drug, individual adults were transferred to a beaker containing a fresh solution of buspirone hydrochloride dissolved in system water $(50 \mathrm{mg} / \mathrm{L})$ and maintained there for $10 \mathrm{~min}$, as previously described (Bencan et al., 2009). Each fish was transferred back to the behavioral apparatus for retesting after the $10 \mathrm{~min}$ drug exposure. The half-life of buspirone is $2-3 \mathrm{~h}$; therefore, baseline measurements preceded drug exposure for all behavioral tests. All assays were performed and analyzed blind with respect to L-R directionality of the epithalamus.

Laser ablation of the parapineal organ. At $3 \mathrm{dpf}, \operatorname{Tg}(\text { foxd } 3: G F P)^{\mathrm{fkg} 17}$ larvae were anesthetized in $0.02 \%$ tricaine (Sigma) and mounted dorsal side up in $1.2 \%$ agarose (Cambrex) coating a $35 \mathrm{~mm}$ Petri dish. The dish was filled with water to cover the immobilized larva, and the $\mathrm{GFP}^{+}$ parapineal was visualized by two-photon fluorescence microscopy ( 885 
A

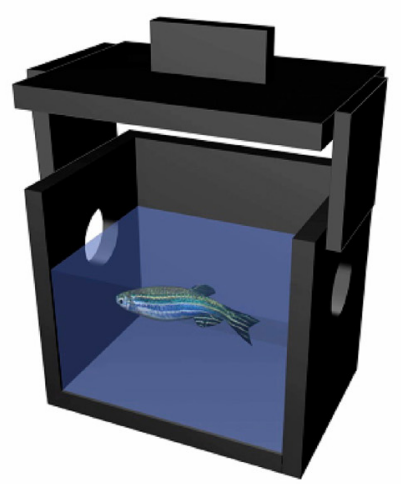

B Latency to emerge
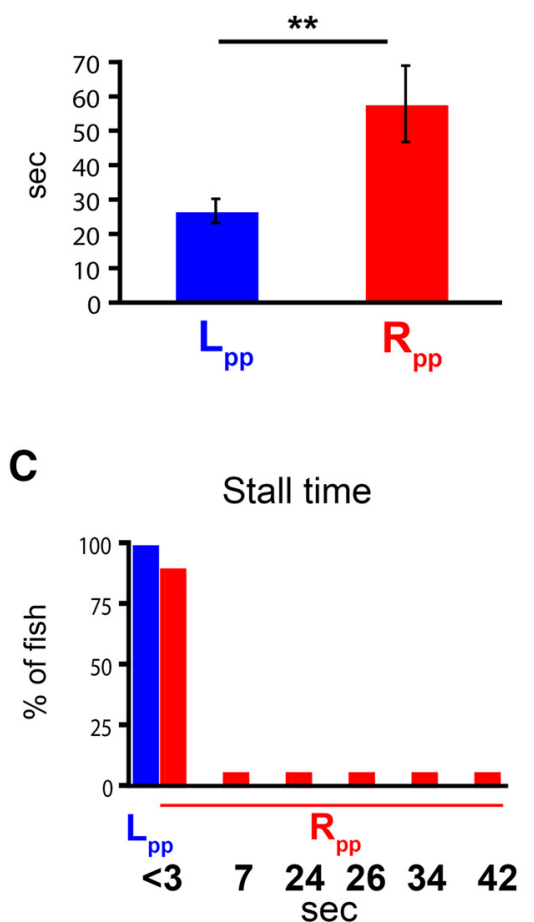

Figure 4. Adults with L-R reversal delay exiting from a confined box. $\boldsymbol{A}$, Schematic representation of the testing apparatus. $\boldsymbol{B}$, Mean $\pm S E$ of the time (seconds) required for $L_{p p}$ and $R_{p p}$ fish to emerge from an exit hole after opening of the lid. $R_{p p}$ adults required significantly more time to find an open exit (Mann-Whitney $U=717, p=0.009$ ). ${ }^{* *} p<0.01$. C, Time (seconds) required for $L_{p p}$ and $R_{p p}$ adults to exit the box completely after finding an opening. A subset of the $R_{p p}$ group (12\%) stalled at the exit hole for extended periods of time. $D$, Video stills of the representative behavior of $L_{p p}$ and $R_{p p}$ adults.

nm excitation from a Spectra-Physics MaiTai HP Ti:Sapphire laser on a Leica TCS-SP5 confocal microscope). Ablation was achieved by focusing the $885 \mathrm{~nm}$ scanning beam onto the parapineal at $35 \%-50 \%$ of full laser power. A single scan pass $(\sim 1 \mathrm{~s})$ was sufficient to destroy the parapineal. Ablation was verified by imaging immediately afterward and again at 8 $\mathrm{dpf}$, and confirmed in dissected adult brains by immunostaining for GFP after behavioral testing. For control larvae, a similar number of cells contralateral to the parapineal were ablated.

Immunofluorescence and analysis of parapineal projections. Larvae or dissected adult brains were fixed in 4\% PFA and processed for wholemount immunofluorescence as previously described (Gamse et al., 2005; Gorelick et al., 2008). The parapineal organ and its axonal projections were labeled with rabbit anti-GFP primary (Sigma) and Alexa 488-conjugated secondary (Invitrogen) antibodies. Anti-acetylated $\alpha$-tubulin primary (Sigma) and DyLite 649-conjugated secondary (Jackson ImmunoResearch Laboratories) antibodies labeled the $\mathrm{dHb}$. Larvae and adult brains were mounted dorsal side up in agarose, and optical sections were captured using the TCS-SP5 confocal equipped with a MaiTai HP Ti:Sapphire laser (SpectraPhysics). Images were acquired with either $40 \times$ NA 0.8 or $25 \times$ NA 0.95 water-immersion objectives. Three-dimensional image reconstruction and measurements of the parapineal projections in $8 \mathrm{dpf}$ larvae were performed using the FilamentTracer module of Imaris 7.2.3 software (Bitplane). The summed length of all projections, the total number of axonal endings (defined as 'terminal points" in FilamentTracer), and the 3D convex hull (i.e., the volume encompassing all projection endpoints) were determined.

Statistical analyses. Statistical analyses were performed using SPSS (SPSS) and Prism (GraphPad Software) software. The nonparametric Mann-Whitney $U$ test was used to compare differences between two unmatched groups. The nonparametric Kruskal-Wallis ANOVA was used to compare differences between three or more unmatched groups and, when significance was obtained, the Dunn's post test was used for pairwise comparisons. When scores followed a Gaussian distribution, a $t$ test for unmatched groups was used. The nonparametric Wilcoxon matched pairs test was used for two matched groups, and Kendall's W test was performed for more than two matched groups. The significance was twotailed for all tests.

\section{Results}

L-R reversal in epithalamic asymmetry affects exploratory behavior

Larvae with spontaneous L-R reversal of epithalamic morphology $(<5 \%)$ were identified using the $\operatorname{Tg}(\text { foxd3:GFP })^{\mathrm{fkg} 17}$ line, in which the pineal and parapineal organs are labeled by GFP (Gilmour et al., 2002). Reversal of asymmetry is indicated by the position of the $\mathrm{R}_{\mathrm{pp}}$. $\mathrm{R}_{\mathrm{pp}}$ individuals are viable as larvae and can be reared to adulthood, allowing comparisons of their behavior to larval and adult zebrafish that have the $\mathrm{L}_{\mathrm{pp}}$.

In the mirror test, individual larvae are placed in a small, rectangular tank with two mirrors as the longer walls and in which L-R eye use in mirror viewing can be readily scored. Adult fish are tested in a proportionally larger tank that also contains lengthwise mirrors. In a prior study, neither the $\mathrm{L}_{\mathrm{pp}}$ nor the $\mathrm{R}_{\mathrm{pp}}$ group of larvae showed a statistically significant bias in eye preference over a 5 min period (Facchin et al., 2009b). However, $\mathrm{R}_{\mathrm{pp}}$ larvae were unexpectedly found to exhibit atypical swimming behavior. We confirmed this finding with a larger group of spontaneously derived $\mathrm{R}_{\mathrm{pp}}$ individuals $(n=$ 48). At $8 \mathrm{dpf}$, these larvae explore the experimental tank in a markedly different way (Fig. $1 A$ ), are delayed in initiating swimming (Fig. $1 B$ ), and cover less total distance (Fig. $1 C$ ) than their $\mathrm{L}_{\mathrm{pp}}$ siblings $(n=40)$. To quantify the difference between swim paths, we devised a metric, the NI, which measures how widely a larva's position is distributed in the testing arena over time (see Materials and Methods). A high NI indicates that the larva ex- 
plores a greater area of the tank, whereas a low NI signifies that its activity is restricted to a more limited region. As depicted in Figure $1 D$, all $\mathrm{L}_{\mathrm{pp}}$ larvae displayed a similarly high NI, whereas $\mathrm{R}_{\mathrm{pp}}$ larvae showed a much wider range of values and, in some cases, individuals remained within a confined region of the tank.

$\mathrm{R}_{\mathrm{pp}}$ adults $(n=38)$ also showed behavioral differences in the mirror test compared with their $\mathrm{L}_{\mathrm{pp}}$ siblings $(n=39)$, including less extensive swim paths (Fig. $1 E)$ and a delay in the onset of swimming (Fig. $1 F$ ). When averaged, the total distance both groups swam was similar $(p>$ 0.05 ; Fig. $1 G$ ) but, because of their reduced exploration of the test tank, the NI was significantly lower for $\mathrm{R}_{\mathrm{pp}}$ adults (Fig. $1 H)$. Thus, differences in exploratory behavior persist from the larval stage to adulthood.

Visual cues alter exploratory behavior It has been suggested that fish interpret a mirror image as a social stimulus representing a conspecific (Desjardins and Fernald, 2010). We tested whether mirror reflections triggered a change in behavioral responses by assaying single adult fish $\left(\mathrm{L}_{\mathrm{pp}}\right.$ and $\mathrm{R}_{\mathrm{pp}}, n=19$ each) under the same conditions with or without mirrors. In the absence of the mirrors, swimming behavior was far more similar between the $\mathrm{L}_{\mathrm{pp}}$ and $\mathrm{R}_{\mathrm{pp}}$ groups (Fig. $2 A, B$ ). As in previous trials, the NI was higher in $\mathrm{L}_{\mathrm{pp}}$ than $\mathrm{R}_{\mathrm{pp}}$ fish in the mirror test (Fig. $2 C$ ), but the value for the $\mathrm{R}_{\mathrm{pp}}$ group significantly shifted upward (Wilcoxon signed ranks $\mathrm{W}=$ $-166, p<0.001$ ) when swim paths were monitored in the absence of mirrors (Fig. $2 D$ ). When additional $\mathrm{L}_{\mathrm{pp}}$ and $\mathrm{R}_{\mathrm{pp}}$ larvae $(n=40$ each $)$ and adults $(n=32$ and 31$)$ were assayed in testing chambers that lacked mirrors, the two groups did not show a statistically significant difference in NI values: $\mathrm{L}_{\mathrm{pp}}$ larvae and adults had values ranging from 6.8 to 9.1 (median 8.2) and 2.3 to 6.7 (median 5.2), respectively, and for $\mathrm{R}_{\mathrm{pp}}$ larvae and adults, the NI ranged from 4.8 to 9.1 (median 8.5) and 2.6 to 6.7 (median 6.2 ), respectively (Mann-Whitney test, $p>0.05$ for each test). These data support the hypothesis that the altered exploratory behavior of zebrafish with L-R reversed epithalamic asymmetry is elicited, in part, by mirror image viewing and is not due to deficits in locomotor activity.

\section{$R_{p p}$ adults exhibit prolonged bottom dwelling in a new environment}

A commonly used assay for measuring stress behavior in adult zebrafish is the "novel tank diving" test (Levin et al., 2007; Egan et al., 2009; Cachat et al., 2010). When first introduced into an unfamiliar tank, wild-type zebrafish have a natural preference for the bottom half but, over time, explore the top half with greater frequency (Levin et al., 2007).

To test a greater number of individuals, we increased the proportion of zebrafish that develop with reversed epithalamic asymmetry to $~ 50 \%$ (Long et al., 2003; Gamse et al.,
2005; Facchin et al., 2009b) by injecting an antisense morpholino against the nodal-related gene southpaw (Long et al., $2003)$ into 1 cell stage $\operatorname{Tg}(\text { foxd3:GFP })^{\mathrm{fkg} 17}$ embryos. $\mathrm{L}_{\mathrm{pp}}$ and $\mathrm{R}_{\mathrm{pp}}$ larvae were separated and the two groups reared to adulthood. Individual adults ( $n=60$ for each group) were introduced into a novel tank, and their swimming behavior was recorded over a 10 min period (Fig. $3 A$ ).

Tracking of $\mathrm{R}_{\mathrm{pp}}$ adults revealed a reduction in their exploratory behavior (Fig. $3 B$ ), with significantly fewer entries into the top half of the tank $(21.8 \pm 1.95$ entries; Fig. $3 C)$ and less time spent there $(55.01 \pm 6.1 \mathrm{~s}$; Fig. $3 D)$ compared with $\mathrm{L}_{\mathrm{pp}}$ siblings $(37.3 \pm 0.03$ entries and $83.52 \pm 7.1 \mathrm{~s}$, respectively).

\section{$R_{p p}$ adults delay exiting from a confined box}

Individual adults were also subjected to a challenging environment by confining them within a small, black Plexiglas box that had two exit holes blocked by a lid (Fig. 4A). Removal of the lid exposed the fish to light and opened exit holes at each end of the box. We recorded the time each fish required to locate an opening (latency to emerge) and fully exit the box (stall time).

$\mathrm{R}_{\mathrm{pp}}$ adults $(n=42)$ showed a significant lag in exiting, spending on average double the amount of time in the box than $\mathrm{L}_{\mathrm{pp}}$ fish $\left(n=50\right.$; Fig. $4 B$ ). Moreover, $12 \%$ of the $\mathrm{R}_{\mathrm{pp}}$ fish entered the opening but remained with only their head protruding outside of the hole for an extended period of time (26.50 $\pm 2.5 \mathrm{~s}$; Fig. 4C) before exiting completely (Fig. 4D). Such stalling behavior was 
A

Entries in top Half

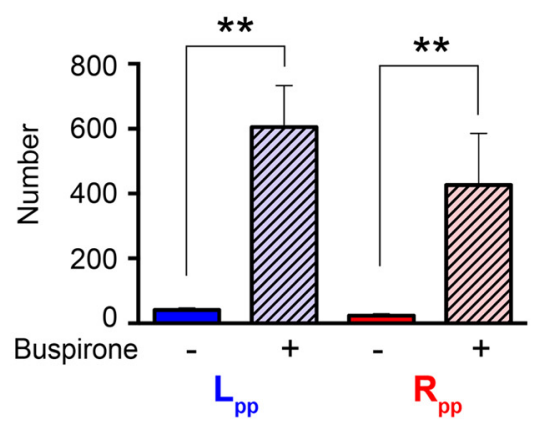

C

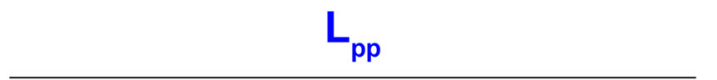

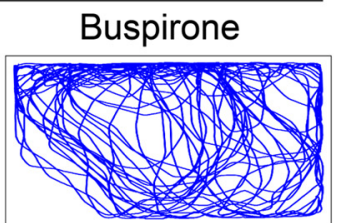
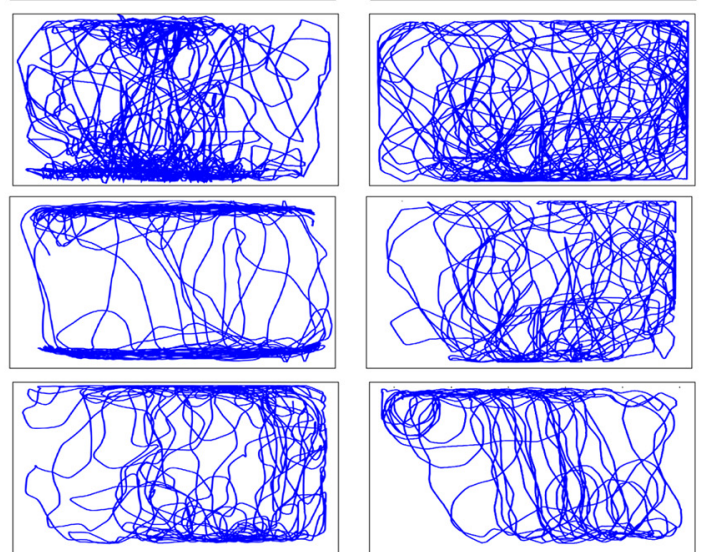

D
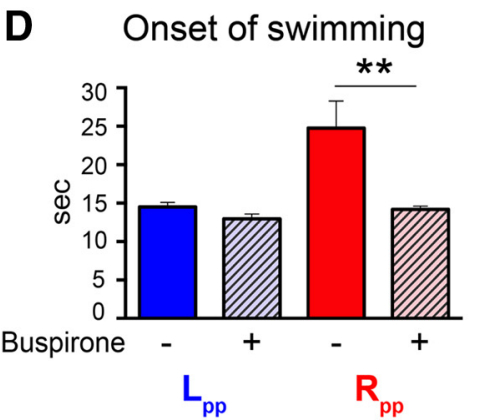

B
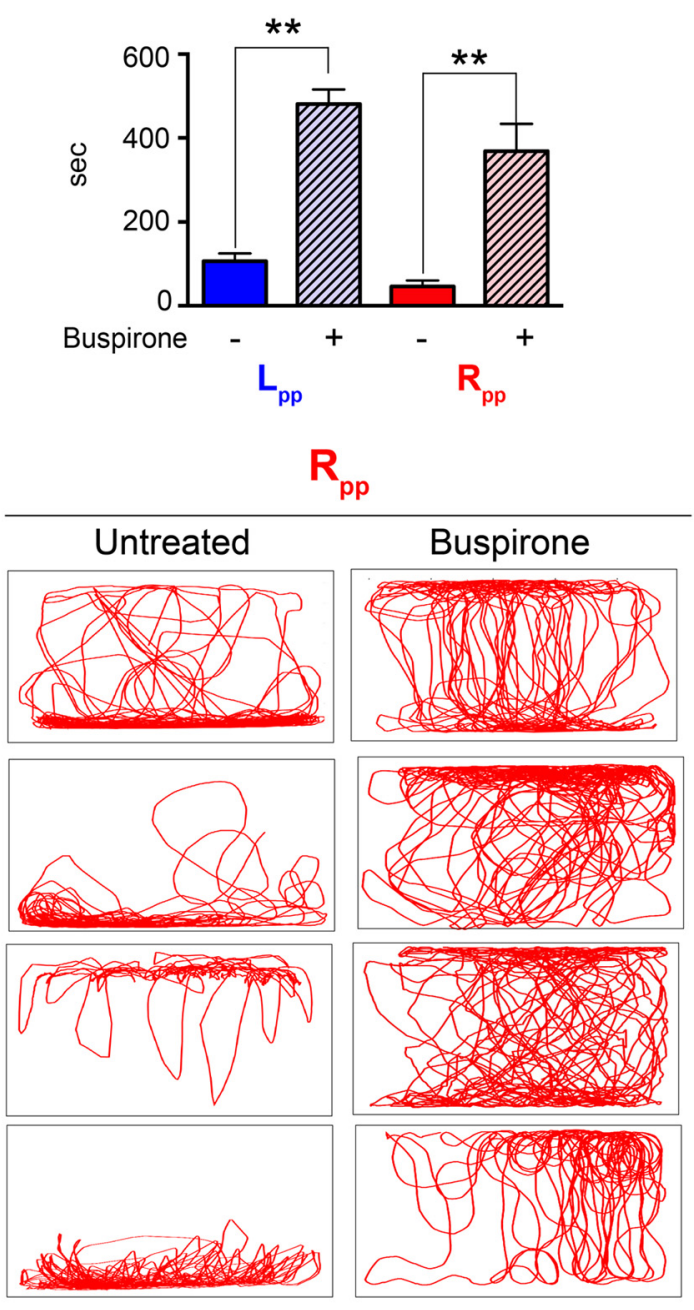

F Latency to emerge

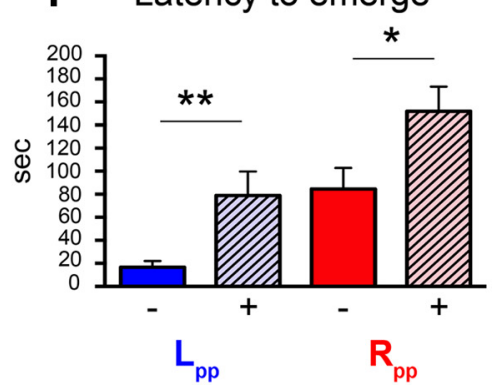

Figure 6. Anxiety-related behavior is suppressed after buspirone treatment. $A, B$, Following exposure to buspirone, $\mathrm{L}_{\mathrm{pp}}$ and $\mathrm{R}_{\mathrm{pp}}$ adults $(n=10$ per group) in the novel tank diving test showed a significant increase in $(\boldsymbol{A})$ entries to the top half of the tank (Wilcoxon signed ranks, $\mathrm{L}_{\mathrm{pp}}: \mathrm{W}=55, p=0.021 ; \mathrm{R}_{\mathrm{p}}: \mathrm{W}=60, p=0.004$ ) and $(\boldsymbol{B})$ spent more time there (Wilcoxon signed ranks, $\mathrm{L}_{\mathrm{pp}}$ : $\left.W=55, p=0.002 ; R_{p p}: W=62, p=0.002\right)$. C, Representative swim paths over 5 min in the mirror test for $L_{p p}(n=11)$ or $R_{p p}(n=10)$ individuals before and after drug treatment. $D$, Relative to $L_{p p}$ siblings, $R_{p p}$ adults showed a significant delay in the onset of swimming after transfer to the mirror test tank (Mann-Whitney $U=20, p=0.01$ ). After drug exposure, the two groups had comparable times (Mann-Whitney $U=34, p=0.2) . E, R_{p p}$ adults had a significantly lower median NI (represented by bars) relative to $L_{p p}$ siblings (Mann-Whitney $U=3, p<0.001$ ) but had similar values after buspirone treatment (Mann-Whitney $U=29, p=0.7$ ). $\boldsymbol{F}$, Buspirone increased the time spent in the confined box for both the $\mathrm{L}_{\mathrm{pp}}$ (Wilcoxon signed ranks $\mathrm{W}=55, p=0.002$; $n=11$ ) and $\mathrm{R}_{\mathrm{pp}}$ (Wilcoxon signed ranks $\mathrm{W}=39, p=0.04 ; n=10$ ) groups. ${ }^{*} p<0.05,{ }^{* *} p<0.01,{ }^{* * *} p<0.001$.

not observed in the $\mathrm{L}_{\mathrm{pp}}$ group $(0.87 \pm 0.1 \mathrm{~s}$; Fig. $4 D)$ or in $\mathrm{WT}$ adults (data not shown).

$R_{p p}$ adults show higher cortisol levels following hypoxic stress

In mammals (Selye, 1976) and fish (Barcellos et al., 2007), stressful events lead to a cascade of physiological changes, including the production and release of cortisol (Cachat et al., 2010). For example, in rainbow trout, lack of oxygen (hypoxia) significantly elevates whole-body cortisol levels (Barry et al., 1995). After adult zebrafish were subjected to hypoxia by removal from water for 4 $\mathrm{min}$, within the next $15 \mathrm{~min}$ whole-body cortisol levels increased $>10$-fold (from $0.1 \pm 0.1 \mathrm{ng}$ per $\mathrm{mg}$ total protein to $1.5 \pm 0.5 \mathrm{ng}$ per mg total protein), and gradually returned to baseline by 60 


\section{Parapineal ablated}
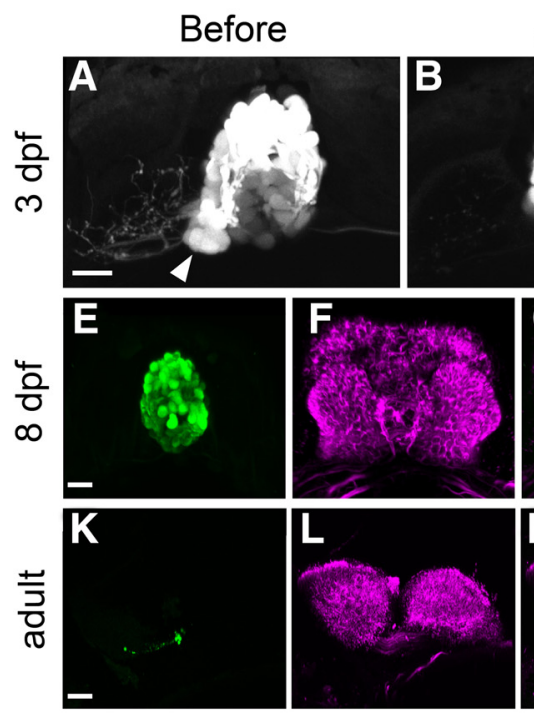

After
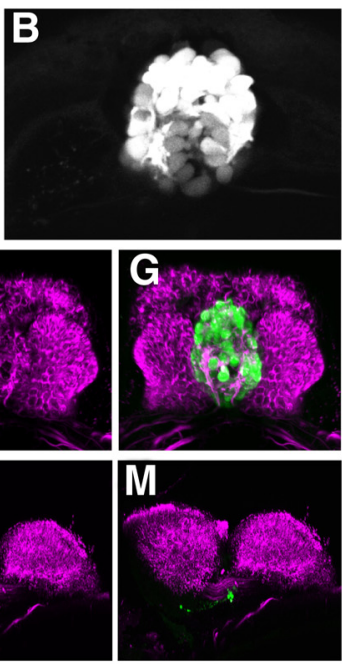

\section{Control ablated}
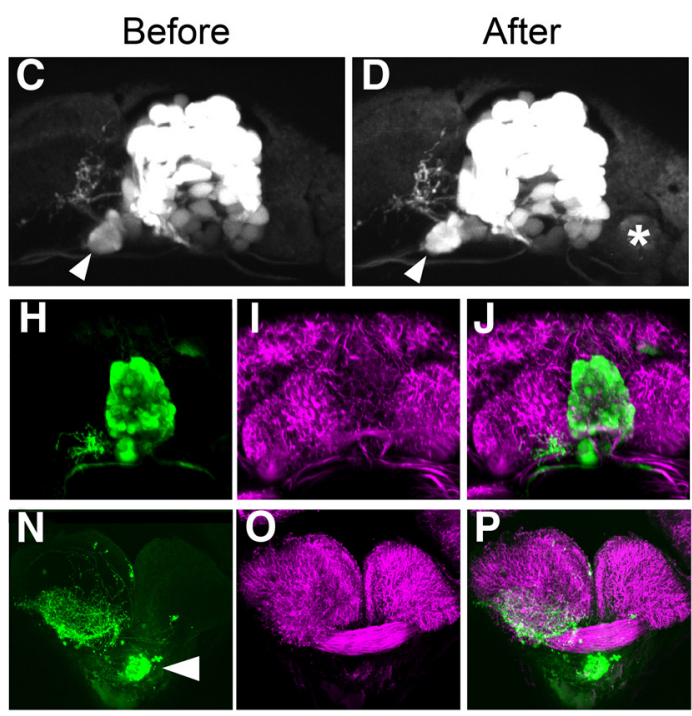

Figure 7. Validation of parapineal ablation in larval and adult zebrafish. $\boldsymbol{A}-\boldsymbol{D}$, Live imaging of the pineal complex in $3 \mathrm{dpf} T g\left(\right.$ foxd3:GFP) ${ }^{\mathrm{fkg} 17}$ larvae before and after $(\boldsymbol{A}, \boldsymbol{B})$ parapineal or $(\boldsymbol{C}, \boldsymbol{D})$ control ablation. Dorsal views, white arrowheads indicate the parapineal. * Contralateral ablation site. Scale bar, $10 \mu \mathrm{m}$. $\boldsymbol{E}-\boldsymbol{J}$, Following behavioral testing, the epithalamic region was immunolabeled in $8 \mathrm{dpf}(\boldsymbol{E}-\boldsymbol{G})$ parapineal ablated and $(\boldsymbol{H}-\boldsymbol{J})$ control ablated larvae and in whole-mount brains dissected from $(\boldsymbol{K}-\boldsymbol{M})$ parapineal ablated and $(\boldsymbol{N}-\boldsymbol{P})$ control ablated adult zebrafish. The pineal complex is labeled with anti-GFP antibody (green) and the dHb neuropil with anti-acetylated $\alpha$-tubulin antibody (magenta). Dorsal views: scale bars: $\boldsymbol{E}-\boldsymbol{J}, 15 \mu \mathrm{m} ; \boldsymbol{K}-\boldsymbol{P}, 50 \mu \mathrm{m}$.

min (Fig. 5A). Although their baseline levels were similar, at 15 min after hypoxia, $\mathrm{R}_{\mathrm{pp}}$ adults had significantly higher wholebody cortisol measurements compared with $\mathrm{L}_{\mathrm{pp}}$ siblings (3.4 \pm 0.02 vs $2.3 \pm 0.1 \mathrm{ng}$ per $\mathrm{mg}$ of total protein; Fig. $5 \mathrm{~B}$ ), indicative of enhanced anxiety.

Exposure to an anxiolytic drug causes $\mathrm{R}_{\mathrm{pp}}$ and $\mathrm{L}_{\mathrm{pp}}$ adults to behave more similarly

It was previously shown that the exploratory behavior of adult zebrafish in the novel tank diving test increased following treatment with certain anxiolytic agents, such as buspirone (Bencan et al., 2009). To confirm that the altered behavior of $\mathrm{R}_{\mathrm{pp}}$ individuals was a consequence of heightened anxiety, we compared their behavior before and after exposure to buspirone in the three assays described above.

Both $\mathrm{L}_{\mathrm{pp}}$ and $\mathrm{R}_{\mathrm{pp}}$ adults ( $n=10$ for each group) showed a significant increase in the number of entries (Fig. 6A) and time spent (Fig. $6 B$ ) in the top half of the novel tank diving test after buspirone treatment. In contrast to their differing responses before treatment (Mann-Whitney $U=21, p=0.01$ for entries and $U=22, p=0.02$ for duration), exploratory behavior was not significantly different between $\mathrm{L}_{\mathrm{pp}}$ and $\mathrm{R}_{\mathrm{pp}}$ adults after exposure to buspirone (Mann-Whitney $U=30, p=0.08$ for entries and $U=40, p=0.303$ for duration), suggesting that the drug had an equivalent effect on reducing anxiety in both groups.

In the mirror assay, and consistent with the above results (Fig. 1$), \mathrm{R}_{\mathrm{pp}}$ adults $(n=10)$ explored less of the test tank relative to their $\mathrm{L}_{\mathrm{pp}}$ siblings $(n=11)$. After buspirone treatment, however, the two groups exhibited similar swim paths over a $5 \mathrm{~min}$ period (Fig. 6C). Buspirone also significantly reduced the onset to swim in $\mathrm{R}_{\mathrm{pp}}$ adults (Fig. 6D) and increased the NI to levels comparable with their $\mathrm{L}_{\mathrm{pp}}$ siblings (Fig. 6E; Mann-Whitney $U=34$, $p=0.14$ ). Treatment with the anxiolytic drug thus specifically enhanced the exploratory activity of $\mathrm{R}_{\mathrm{pp}}$ zebrafish.

Buspirone also had a significant, albeit unexpected, effect on behavior in the confined box test. After exposure to the drug, $\mathrm{L}_{\mathrm{pp}}(n=11)$ and $\mathrm{R}_{\mathrm{pp}}(n=10)$ adults required more time (2- to 4 -fold longer) to emerge from the box than before treatment. These results indicate that buspirone delays escape from a confining environment for both groups (Fig. $6 F$ ).

\section{Parapineal ablation also reduces exploratory behavior}

To examine whether the epithalamus mediates the altered behaviors, we perturbed L-R differences only in this region of the brain by eliminating the parapineal in $3 \mathrm{dpf} T g(f o x d 3: G F P)^{\mathrm{fkg} 17}$ larvae (Fig. $7 A, B$ ). In larvae serving as controls, a similar number of cells were ablated to the right of the pineal, contralateral to the parapineal (Fig. $7 C, D$ ). Laser-mediated ablation of the parapineal causes the adjacent left $\mathrm{dHb}$ to develop more similarly to the right one, with a smaller size, distinct molecular profile, and altered neural connections (Concha et al., 2003; Gamse et al., 2003, 2005; Kuan et al., 2007b). Following behavioral testing, ablation was confirmed by anti-GFP immunolabeling in $8 \mathrm{dpf}$ larvae (Fig. $7 E-J$ ) and in adults (Fig. $7 K-P$ ).

Parapineal ablated $T g(f \circ x d 3: G F P)^{\text {fkg17 }}$ larvae $(n=52)$ assayed in the mirror test showed less exploratory activity at $8 \mathrm{dpf}$ (Fig. $8 A)$ compared with control ablated siblings $(n=51)$. Specifically, they showed a delayed onset in navigation (Fig. $8 B$ ), a dramatic reduction in the distance covered over $5 \mathrm{~min}$ (Fig. $8 C$ ) and greater variation in the NI (Fig. $8 D$ ). However, when tested without mirrors, the onset in navigation, total distance covered over $5 \mathrm{~min}$, and NI were comparable between the parapineal and control ablated groups (Mann-Whitney test, $p>0.05$ for all).

Both groups were reared and also assayed as adults $(n=22$ each). Those lacking the parapineal showed reduced exploratory behavior (Fig. $8 E, F$ ), but, in the absence of mirrors, their activity was similar to the controls (Fig. 8 E, G). Parapineal ablated adults also required more time to exit the confined box compared with the control ablated adults (Fig. $8 H$ ). Overall, the behavioral responses of individuals lacking the parapineal resembled those of $\mathrm{R}_{\mathrm{pp}}$ larvae and adults. 
A Control ablated
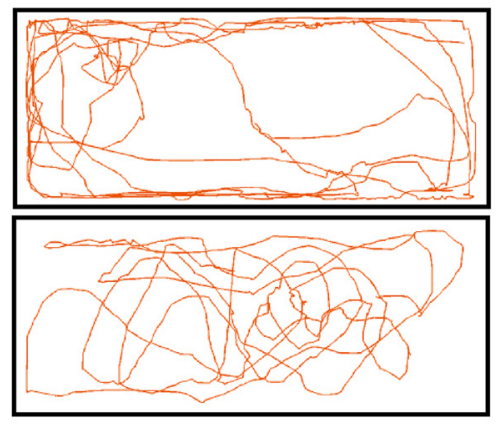

Parapineal ablated larvae

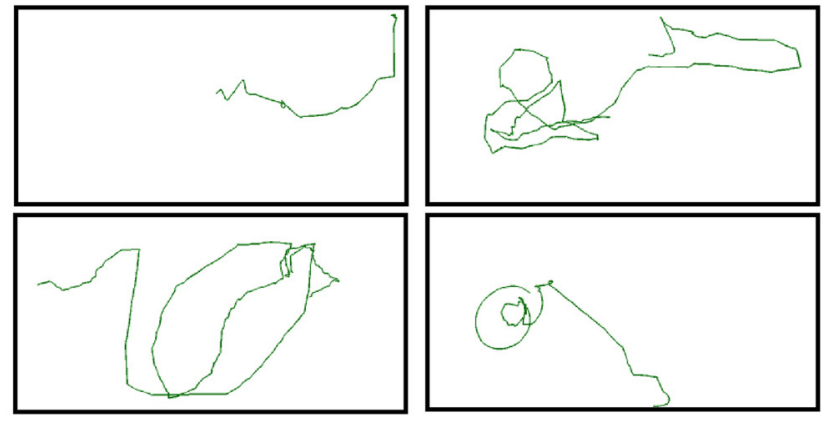

C

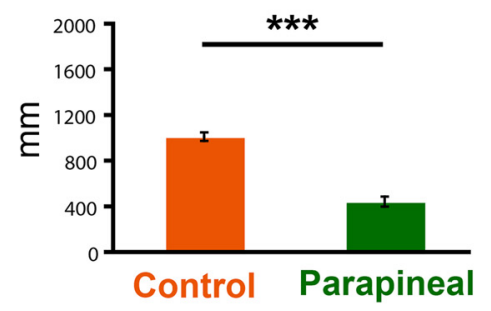

D

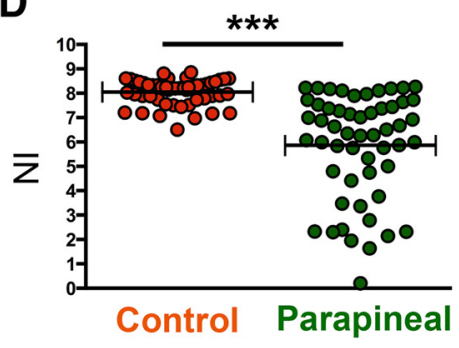

E Parapineal ablated adults Mirrors
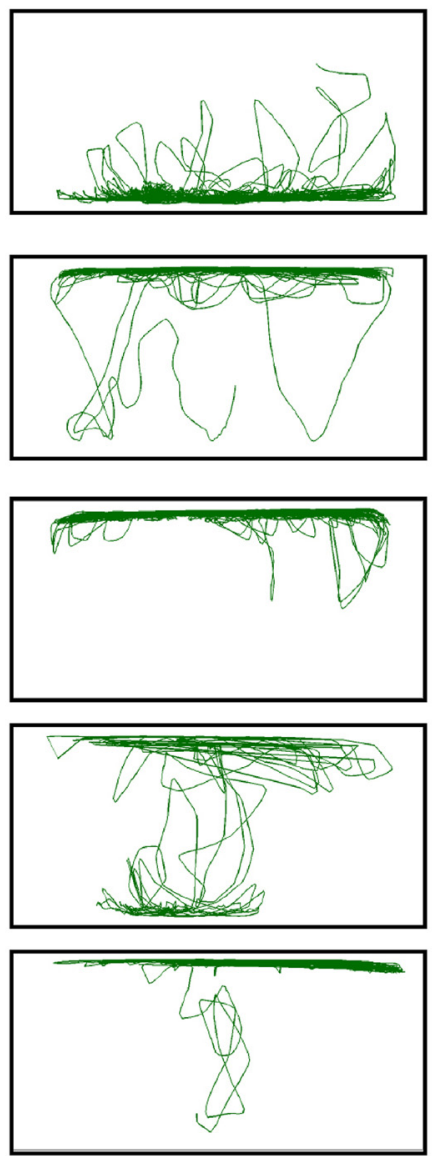

No mirrors
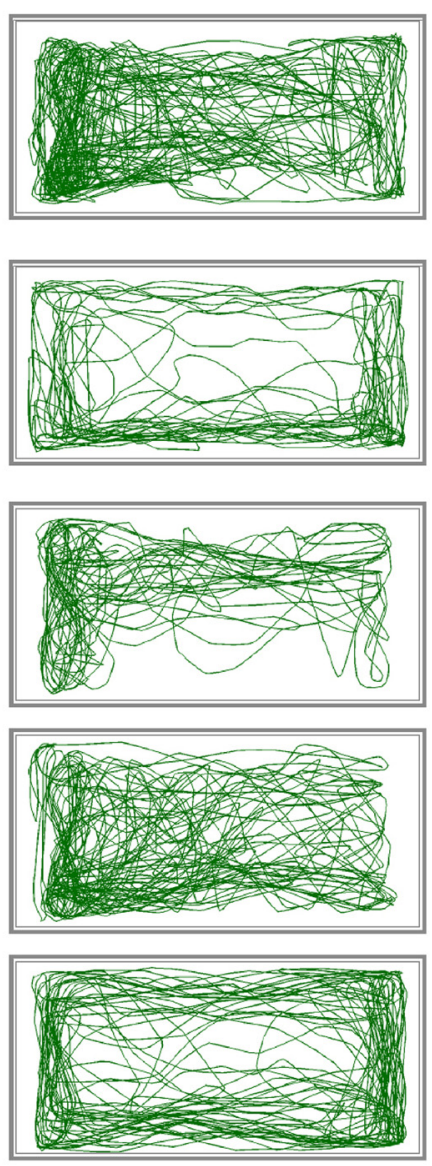

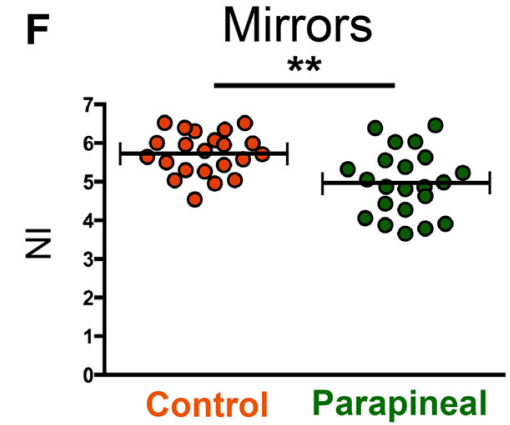

G No mirrors

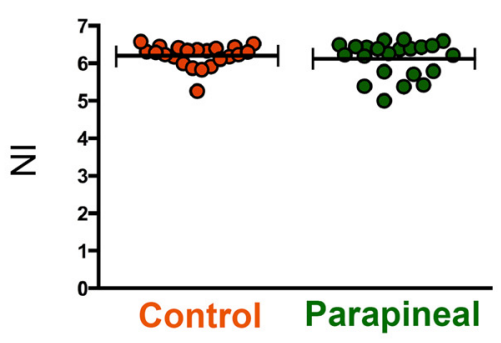

H Latency to emerge

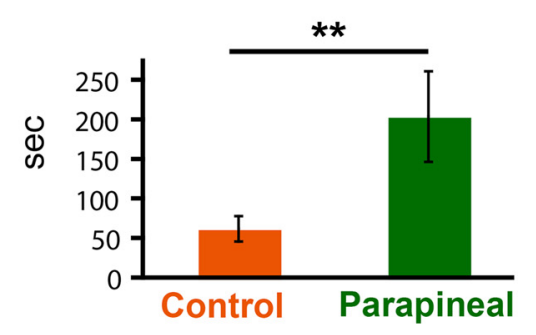

Figure 8. Exploratory behavior is perturbed in zebrafish lacking the parapineal. $\boldsymbol{A}$, Representative swim paths over 5 min in the mirror test for control ablated and parapineal ablated larvae. $\boldsymbol{B}$, $\boldsymbol{C}$, The mean \pm SE in $(\boldsymbol{B})$ the onset of swimming (seconds) and in $(\boldsymbol{C})$ total distance traveled (millimeters) over 5 min for control and parapineal ablated larvae. Larvae lacking the parapineal showed a delay in the onset of swimming (Mann-Whitney $U=985, p=0.025$ ) and a decrease in swim distance (Mann-Whitney $U=263, p<0.001$ ) relative to (Figure legend continues.) 


\section{Axonal projections from the parapineal are more variable in $\mathbf{R}_{\mathrm{pp}}$ larvae}

In parapineal ablated individuals, the left and right habenular nuclei show nearly symmetric morphology (Concha et al., 2003; Gamse et al., 2003). It was therefore unexpected that their behavior would be similar to that of $\mathrm{R}_{\mathrm{pp}}$ fish with $\mathrm{L}-\mathrm{R}$ reversed, asymmetric $\mathrm{dHb}$. This led us to explore whether abnormal positioning of the parapineal has other consequences that may account for behavioral responses resembling those of zebrafish lacking the parapineal.

The parapineal is usually situated just left of the pineal, and its neurons extend axonal projections exclusively to the left $\mathrm{dHb}$ (Yáñez et al., 1996; Concha and Wilson, 2001; Concha et al., 2003; Gamse et al., 2003; Signore et al., 2009). Using multiphoton confocal microscopy and 3D image analysis, we selectively traced and measured neuronal projections emanating from left $(n=23$; Fig. $9 A-C)$ or right $(n=20$; Fig. $9 D-F)$ positioned parapineals in 8 dpf larvae.

Overall, axonal projection patterns were less variable when the parapineal was situated to the left of the pineal (Fig. 9G-J). When the parapineal was located on the right, a wide array of patterns was observed, ranging from severely truncated arborization to a near mirror image of left parapineal axonal morphology (Fig. $9 K-M$ ). In $15 \%$ (3 of 20) of larval brains, axons extended bilaterally from the right-positioned parapineal to both $\mathrm{dHb}$ (Fig. $9 N$ ), a feature never observed in the brains of $\mathrm{L}_{\mathrm{pp}}$ larvae. The volume encompassing the axonal projections ("convex hull," Fig. 9O) and their average total length (Fig. 9P) was significantly smaller in the $\mathrm{R}_{\mathrm{pp}}$ larval group. A decrease in axon terminal points relative to $L_{p p}$ larvae (Fig. 9Q) confirmed a reduction in branching. The analysis of parapineal projections indicates that L-R reversal of epithalamic asymmetry does not necessarily correspond with a complete mirror image reversal and that some $\mathrm{R}_{\mathrm{pp}}$ larvae have highly aberrant axonal morphology.

\section{Discussion}

The present study demonstrates that L-R reversal or loss of epithalamic asymmetry reduces the exploratory behavior of larval and adult zebrafish when exposed to novel environments. Moreover, adults with reversed L-R asymmetry exhibit higher cortisol levels in response to stress. However, after treatment with the anti-anxiety agent buspirone, these adults behave more similarly to their unaffected siblings.

Although the epithalamus of diverse fish species exhibit L-R differences (Concha and Wilson, 2001; Kuan et al., 2007a; Signore et al., 2009; Gutiérrez-Ibáñez et al., 2011), little is known about their functional significance. Neurons in the left and right $\mathrm{dHb}$ are differentially activated following exposure to odors or light (Dreosti et al., 2014; Jetti et al., 2014), but the behavioral consequences are unclear. L-R asymmetry has been correlated with lateralized behaviors, such as eye preference and bias in turning direction (Barth et al., 2005; Dadda et al., 2010; Gutiérrez-Ibáñez et al., 2011). However, spontaneous reversal of

\footnotetext{
(Figure legend continued.) the controls. D, Overall, larvae lacking the parapineal explored a more limited area of the testing tank (Mann-Whitney $U=324, p<0.001$ ) as indicated by the lower median of the NI relative to control ablated larvae. $\boldsymbol{E}$, Representative swim paths over 5 $\min$ for the same group of parapineal ablated adults assayed with or without mirrors. $\boldsymbol{F}, \boldsymbol{G}$, Distribution of NI values $(\boldsymbol{F})$ with (Mann-Whitney $U=114, p=0.003$ ) or $(\boldsymbol{G})$ without mirrors (Mann-Whitney $U=235, p>0.05$ ). $\boldsymbol{H}$, Mean \pm SE of the latency to emerge from a confined box (seconds) for both adult ablated groups (Mann-Whitney $U=82, p=0.008$ ). ${ }^{* * *} p<$ 0.001. ${ }^{* *} p<0.01 .{ }^{*} p<0.05$.
}

epithalamic asymmetry does not seem to alter a variety of motor behaviors in larvae, including eye use in mirror viewing or responses to lateralized stimuli but, rather, delays the initiation and extent of exploratory behavior (Facchin et al., 2009b).

We devised the NI to quantify how an individual fish explores a tank space over the testing period. This measurement indicates that the direction of L-R asymmetry affects exploratory behavior at larval and adult stages. A subset of $\mathrm{R}_{\mathrm{pp}}$ larvae with extremely low NI values remained in highly restricted regions of the assay tank, akin to freezing, whereas half of $\mathrm{R}_{\mathrm{pp}}$ adults swam in close proximity to the mirrored walls, in a behavior resembling thigmotaxis (Blaser et al., 2010). Both freezing and thigmotaxis are thought to be indicators of fear/anxiety (Maximino et al., 2010). Importantly, under similar testing conditions, but with only the mirrors removed, the NI distribution of $\mathrm{R}_{\mathrm{pp}}$ individuals was more similar to $\mathrm{L}_{\mathrm{pp}}$ siblings. In many fish species, mirror image viewing provokes aggressive behavior and, in cichlids, it activates the amygdala (Desjardins and Fernald, 2010), suggesting that fish experience fear when confronted with their own reflection.

A widely used behavioral measure of anxiety in zebrafish has been their swimming activity when placed in a novel tank. Initially, WT adults show a preference for the bottom half but, over time, explore the top half with greater frequency (Levin et al., 2007; Egan et al., 2009; Cachat et al., 2010). Treatment with drugs that reduce anxiety results in less bottom dwelling (Bencan et al., 2009; Cachat et al., 2011), whereas drugs that increase anxiety prolong it (Levin et al., 2007; Sackerman et al., 2010). Consistent with a heighted state of anxiety, we found that $\mathrm{R}_{\mathrm{pp}}$ adults spend more time in the bottom half of a novel tank relative to $\mathrm{L}_{\mathrm{pp}}$ siblings.

The behavioral assays suggest that reversing epithalamic L-R asymmetry in larval and adult zebrafish corresponds with increased anxiety. Two studies previously showed that the $\mathrm{dHb}$ are important for controlling experience-dependent fear responses (Agetsuma et al., 2010; Lee et al., 2010). Silencing the activity of a lateral subset of $\mathrm{dHb}$ neurons that predominately project to the dorsal interpeduncular nucleus (IPN) causes adult zebrafish to freeze when presented with a conditioned fear stimulus (Agetsuma et al., 2010). Neurons within the dorsal IPN project to the hindbrain griseum centrale (Okamoto et al., 2012), which is thought to be functionally analogous to regions in the mammalian brain involved in coping with stressful conditions (Bandler et al., 2000).

A direct readout of anxiety is the level of whole-body cortisol, the major neuroendocrine stress hormone. Baseline measures of cortisol were comparable between $\mathrm{L}_{\mathrm{pp}}$ and $\mathrm{R}_{\mathrm{pp}}$ adults, and both showed peak cortisol activity 15 min following stress. However, $R_{p p}$ adults had significantly elevated cortisol levels relative to $L_{p p}$ siblings, characteristic of a higher state of anxiety. Consistent with this, exposure of $\mathrm{R}_{\mathrm{pp}}$ adults to buspirone, just before behavioral testing, resulted in a significant increase in exploratory behavior in the mirror tank and a reduction in bottom dwelling in the novel tank diving test, to levels indistinguishable from $\mathrm{L}_{\mathrm{pp}}$ siblings.

Further evidence of the altered behavior of $\mathrm{R}_{\mathrm{pp}}$ adults came from monitoring their emergence from a confined, dark space to a larger, bright one. Zebrafish are known to exhibit scototaxis, a preference for dark over bright environments (Serra et al., 1999; Rosemberg et al., 2011), and avoidance of light is used as a measure of anxiety (Blaser et al., 2010; Magno et al., 2015). Additionally, adult zebrafish exposed to buspirone show a preference for the illuminated side of a tank over a dark side (Lau et al., 2011). $\mathrm{R}_{\mathrm{pp}}$ adults took significantly longer to exit the box and, in several 

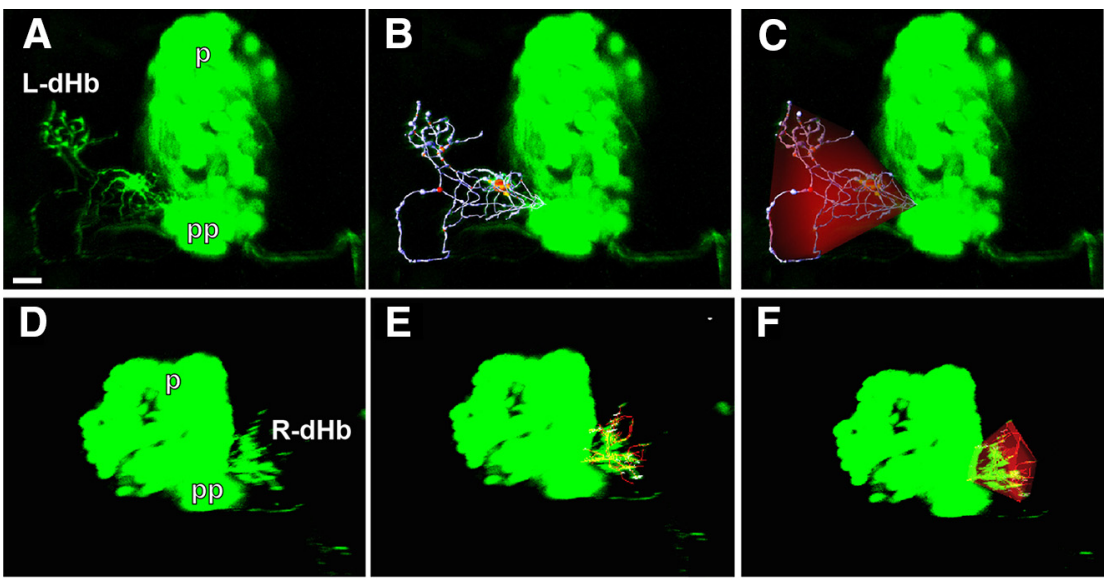

$\mathbf{L}_{\mathrm{pp}}$
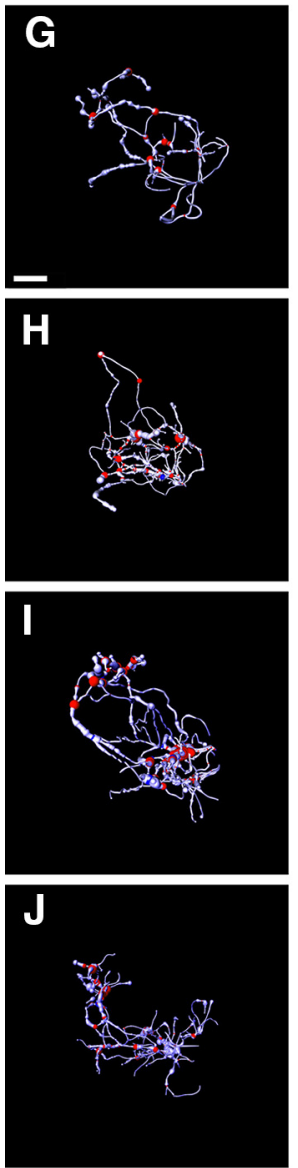
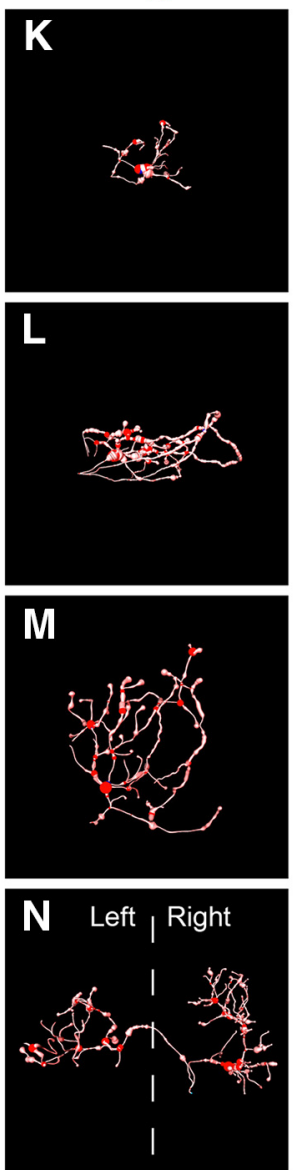

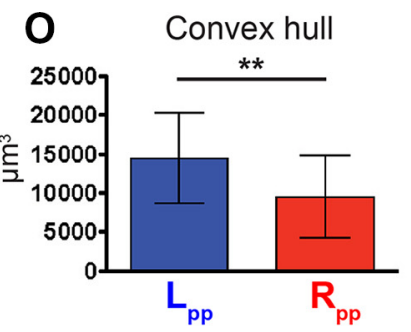

$\mathbf{P}$

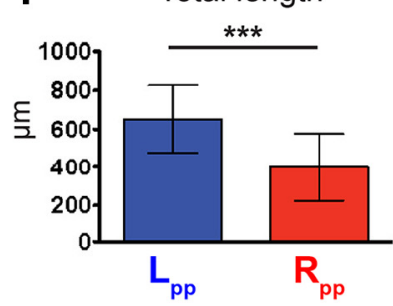

Q Terminal points

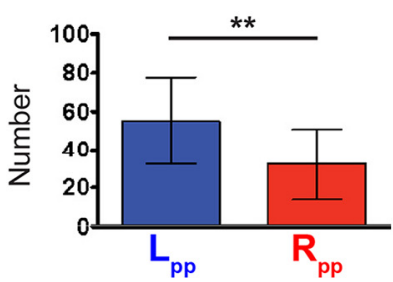

Figure 9. Abnormal axonal projection patterns in larvae with $L-R$ reversal. $\boldsymbol{A}-\boldsymbol{F}$, Dorsolateral view of the pineal and parapineal in $\mathrm{L}_{\mathrm{pp}}(\boldsymbol{A}-\boldsymbol{C})$ and $\mathrm{R}_{\mathrm{pp}}(\boldsymbol{D}-\boldsymbol{F}) 8 \mathrm{dpf} \operatorname{Tg}(\text { foxd3:GFP) })^{\mathrm{fkg} 17}$ larvae. $\boldsymbol{A}, \boldsymbol{D}$, Anti-GFP immunolabeling reveals parapineal axonal projections to the $(\boldsymbol{A})$ left and $(\boldsymbol{D})$ right $\mathrm{dHb}$ that can be $(\boldsymbol{B}, \boldsymbol{E})$ traced using the FilamentTracer module of Imaris software. $\boldsymbol{C}, \boldsymbol{F}$, The volume corresponding to the convex hull is visualized in red. $\mathbf{G}-\boldsymbol{N}$, Tracing of representative axonal projections from $(\mathbf{G}-\boldsymbol{J})$ left positioned and $(\boldsymbol{K}-\boldsymbol{N})$ right positioned parapineals to the adjacent $\mathrm{dHb}$. Efferents were more variable from parapineals situated on the right and $(\boldsymbol{N})$ extended to both the left and right $\mathrm{dHb}$ in $15 \%$ of larvae. Dashed line indicates the brain midline. Scale bars, $10 \mu \mathrm{m}$. $\boldsymbol{0}$, The convex hull volume $\left(\mu \mathrm{m}^{3}\right)\left(t_{(38)}=2.78, p=0.009\right),(\boldsymbol{P})$ total length of axonal extensions $(\mu \mathrm{m})\left(t_{(38)}=4.5, p<0.001\right)$, and (Q) number of terminal points $\left(t_{(38)}=3.36, p=0.002\right)$ were significantly reduced in the $R_{p p}$ group. $\mathbf{0} \mathbf{Q}$, Graphs represent mean \pm SD. ${ }^{* * *} p<0.001$. ${ }^{* *} p<0.01$.

cases, stalled for a prolonged time at the opening. On the basis of the studies on scototaxis, a plausible explanation is that the delayed entry of $\mathrm{R}_{\mathrm{pp}}$ adults into a brightly lit area also signifies enhanced fearfulness. Pretreatment of $L_{p p}$ and $R_{p p}$ adults to bu- spirone before the assay, however, prolonged the time to exit rather than shortened it for both groups. The confined box may present a more stressful environment than the other testing arenas and, by reducing anxiety, buspirone treatment lengthens the time spent in an otherwise stress inducing space. This assay therefore presents the fish with two distinct and conflicting stressors (i.e., light and confinement), possibly accounting for the additive effect on the latency to emerge exhibited by $\mathrm{R}_{\mathrm{pp}}$ individuals after drug treatment.

The epithalamus is the only region of the zebrafish brain that has been found so far to exhibit prominent L-R differences, and features such as the position of the parapineal or asymmetry of habenular gene expression are taken to represent the left or right bias of the entire CNS. Because it is unknown whether the brains of L-R reversed individuals have other alterations, perturbation of habenular identity by removal of only the parapineal provides a more selective means of testing the relevance of epithalamic asymmetry. The parapineal mediates L-R differences in habenular morphology, cell proliferation, and neuronal subpopulations (Concha et al., 2003; Gamse et al., 2003) and dHb connections with the target IPN (Aizawa et al., 2005; Gamse et al., 2005; Kuan et al., 2007b). Through ablation experiments, we demonstrated that the parapineal, presumably through its influence on habenular L-R asymmetry, also affects exploratory behavior.

In parapineal ablated larvae, habenular identity is altered and the majority of $\mathrm{dHb}$ neurons innervate the ventral IPN (Gamse et al., 2005; Kuan et al., 2007a,b). Lack of habenular input to the dorsal IPN most likely has the same effect as silencing neuronal activity in the lateral subdomain (Agetsuma et al., 2010; Lee et al., 2010), thereby disrupting the modulatory role of the $\mathrm{dHb}$ on the circuitry that mediates fear responses.

The reduced exploratory behavior of parapineal ablated individuals in the mirror test and prolonged time to emerge from the confined box are consistent with the freezing behavior that was observed in dHb-impaired juveniles (Lee et al., 2010) and adults (Agetsuma et al., 2010). Loss of parapineal input thus appears sufficient to trigger changes in habenular function that lead to fearful behavior.

A puzzling finding is that fish with L-R reversals of epithalamic asymmetry show similar behavioral deficits as those with more symmetric $\mathrm{dHb}$ due to removal of the parapineal. In the former, habenular connectivity to the IPN is intact but merely 
reversed in directionality, whereas in the latter, projections to the dorsal IPN are greatly reduced (Gamse et al., 2005; Kuan et al., 2007b). Although it is unknown what other neuroanatomical changes accompany reversed directionality of the epithalamus, analyses of projections from the parapineal indicate that L-R reversal does not necessarily generate a mirror image pattern in axonal morphology. Not only are axonal projections frequently truncated when the parapineal is located on the right side, but, in some larval brains, neuronal processes extend bilaterally to both the left and right $\mathrm{dHb}$. Such altered patterns of innervation could have consequences on habenular input to the IPN and on the modulation of its downstream targets. Diversity in parapineal axonal morphology may, in part, account for the increased variability we observed in the behavior of $\mathrm{R}_{\mathrm{pp}}$ larvae, ranging from highly aberrant to responses indistinguishable from $\mathrm{L}_{\mathrm{pp}}$ controls. Experiments to correlate a given innervation pattern with behavioral severity did not reveal a clear-cut correspondence (data not shown), suggesting that synaptic input to the $\mathrm{dHb}$ is affected in additional ways.

As in zebrafish with reversed epithalamic asymmetry, mice with situs inversus, such as inversus viscerum (iv) mutants, do not show a L-R reversal in hemispheric differences found in the hippocampus. For example, instead of the usual asymmetric distribution of the NMDA receptor subunit NR2B in synapses on left and right CA1 pyramidal neurons, iv/iv homozygotes exhibit right isomerism (Wu et al., 2005). Not only does this alter L-R asymmetry in synaptic plasticity (Kawakami et al., 2008), but $i v / i v$ mice also show impaired memory in spatial learning tests (Goto et al., 2010). Therefore, in both fish and mice, the assumption that reversed laterality is associated with a complete mirror image reversal of neuroanatomy and synaptic activity is unwarranted.

Linking L-R asymmetry in the brain with mechanisms that modulate fear responses may confer a functional advantage. One intriguing hypothesis, the valence hypothesis, proposes that the left and right sides of the brain are specialized for responding to positive and negative stimuli (Davidson, 1984). In the rat, subnuclei of the left and right amygdala show differences in protein kinase $C \beta I I$ levels, which correlate with the length of freezing in a fear-conditioning paradigm (Orman and Stewart, 2007). Norepinephrine levels and expression of the immediate early gene arc are also preferentially increased in the right basolateral amygdala following exposure to aversive stimuli. Conversely, an unanticipated reward results in a rise in norepinephrine in the left basolateral amygdala (Young and Williams, 2010, 2013). Thus, lateralized specializations may allow the same neural circuitry to interpret negative and positive stimuli differently on the left and right sides of the brain and elicit the appropriate response. Whether the $\mathrm{dHb}$ mediate a similar L-R bias in how zebrafish react to aversive versus rewarding stimuli remains to be determined. Genetic approaches for selective disruption of asymmetrically distributed $\mathrm{dHb}$ neuronal subpopulations may provide an answer.

\section{Notes}

Supplemental material for this article is available at https://emb.carnegiescience.edu/science/faculty/marnie-halpern/movies and contains movies depicting the behavior of larval and adult zebrafish in the mirror assay and adults in the confined box.

\section{References}

Agetsuma M, Aizawa H, Aoki T, Nakayama R, Takahoko M, Goto M, Sassa T, Amo R, Shiraki T, Kawakami K, Hosoya T, Higashijima S, Okamoto H (2010) The habenula is crucial for experience-dependent modification of fear responses in zebrafish. Nat Neurosci 13:1354-1356. CrossRef Medline

Aizawa H, Bianco IH, Hamaoka T, Miyashita T, Uemura O, Concha ML, Russell C, Wilson SW, Okamoto H (2005) Laterotopic representation of left-right information onto the dorso-ventral axis of a zebrafish midbrain target nucleus. Curr Biol 15:238-243. CrossRef Medline

Aizawa H, Goto M, Sato T, Okamoto H (2007) Temporally regulated asymmetric neurogenesis causes left-right difference in the zebrafish habenular structures. Dev Cell 12:87-98. CrossRef Medline

Bandler R, Keay KA, Floyd N, Price J (2000) Central circuits mediating patterned autonomic activity during active vs. passive emotional coping. Brain Res Bull 53:95-104. CrossRef Medline

Barcellos L, Ritter F, Kreutz L, Quevedo R, Bolognesi da Silva L, Bedin A, Finco J, Cericato L (2007) Whole-body cortisol increases after direct and visual contact with a predator in zebrafish, Danio rerio. Aquaculture 272:774. CrossRef

Barry TP, Malison JA, Held JA, Parrish JJ (1995) Ontogeny of the cortisol stress response in larval rainbow trout. Gen Comp Endocrinol 97:57-65. CrossRef Medline

Barth KA, Miklosi A, Watkins J, Bianco IH, Wilson SW, Andrew RJ (2005) fsi zebrafish show concordant reversal of laterality of viscera, neuroanatomy, and a subset of behavioral responses. Curr Biol 15:844-850. CrossRef Medline

Bencan Z, Sledge D, Levin ED (2009) Buspirone, chlordiazepoxide and diazepam effects in a zebrafish model of anxiety. Pharmacol Biochem Behav 94:75-80. CrossRef Medline

Blaser RE, Chadwick L, McGinnis GC (2010) Behavioral measures of anxiety in zebrafish (Danio rerio). Behav Brain Res 208:56-62. CrossRef Medline

Cachat J, Stewart A, Grossman L, Gaikwad S, Kadri F, Chung KM, Wu N, Wong K, Roy S, Suciu C, Goodspeed J, Elegante M, Bartels B, Elkhayat S, Tien D, Tan J, Denmark A, Gilder T, Kyzar E, Dileo J, et al. (2010) Measuring behavioral and endocrine responses to novelty stress in adult zebrafish. Nat Protoc 5:1786-1799. CrossRef Medline

Cachat J, Canavello P, Elegante M, Bartels B, Elkhayat S, Hart P, Tien A, Tien D, Beeson E, Mohnot S, Laffoon A, Stewart A, Gaikwad S, Wong K, Haymore W, Kalueff A (2011) Modeling stress and anxiety in zebrafish. In: Zebrafish models in neurobehavioral research (Kalueff AV, Cachat JM, eds), pp 73-88. New York: Humana.

Cochella L, Tursun B, Hsieh YW, Galindo S, Johnston RJ, Chuang CF, Hobert O (2014) Two distinct types of neuronal asymmetries are controlled by the Caenorhabditis elegans zinc finger transcription factor die-1. Genes Dev 28:34-43. CrossRef Medline

Concha ML, Wilson SW (2001) Asymmetry in the epithalamus of vertebrates. J Anat 199:63-84. CrossRef Medline

Concha ML, Burdine RD, Russell C, Schier AF, Wilson SW (2000) A nodal signaling pathway regulates the laterality of neuroanatomical asymmetries in the zebrafish forebrain. Neuron 28:399-409. CrossRef Medline

Concha ML, Russell C, Regan JC, Tawk M, Sidi S, Gilmour DT, Kapsimali M, Sumoy L, Goldstone K, Amaya E, Kimelman D, Nicolson T, Gründer S, Gomperts M, Clarke JD, Wilson SW (2003) Local tissue interactions across the dorsal midline of the forebrain establish CNS laterality. Neuron 39:423-438. CrossRef Medline

Dadda M, Domenichini A, Piffer L, Argenton F, Bisazza A (2010) Early differences in epithalamic left-right asymmetry influence lateralization and personality of adult zebrafish. Behav Brain Res 206:208-215. CrossRef Medline

Davidson RJ (1984) Affect, cognition, and hemispheric specialization. In: Emotions, cognition, and behavior (Izard CE, Kagan J, Zajonc RB, eds), pp 1-46. New York: Cambridge UP.

Deng C, Rogers LJ (1997) Differential contributions of the two visual pathways to functional lateralization in chicks. Behav Brain Res 87:173-182. CrossRef Medline

Desjardins JK, Fernald RD (2010) What do fish make of mirror images? Biol Lett 6:744-747. CrossRef Medline

Dreosti E, Vendrell Llopis N, Carl M, Yaksi E, Wilson SW (2014) Left-right asymmetry is required for the habenulae to respond to both visual and olfactory stimuli. Curr Biol 24:440-445. CrossRef Medline

Egan RJ, Bergner CL, Hart PC, Cachat JM, Canavello PR, Elegante MF, Elkhayat SI, Bartels BK, Tien AK, Tien DH, Mohnot S, Beeson E, Glasgow E, Amri H, Zukowska Z, Kalueff AV (2009) Understanding behavioral and physiological phenotypes of stress and anxiety in zebrafish. Behav Brain Res 205:38-44. CrossRef Medline 
Facchin L, Argenton F, Bisazza A (2009a) Lines of Danio rerio selected for opposite behavioural lateralization show differences in anatomical leftright asymmetries. Behav Brain Res 197:157-165. CrossRef Medline

Facchin L, Burgess HA, Siddiqi M, Granato M, Halpern ME (2009b) Determining the function of zebrafish epithalamic asymmetry. Philos Trans R Soc Lond B Biol Sci 364:1021-1032. CrossRef Medline

Gamse JT, Thisse C, Thisse B, Halpern ME (2003) The parapineal mediates left-right asymmetry in the zebrafish diencephalon. Development 130 : 1059-1068. CrossRef Medline

Gamse JT, Kuan YS, Macurak M, Brösamle C, Thisse B, Thisse C, Halpern ME (2005) Directional asymmetry of the zebrafish epithalamus guides dorsoventral innervation of the midbrain target. Development 132:48694881. CrossRef Medline

Gilmour DT, Maischein HM, Nüsslein-Volhard C (2002) Migration and function of a glial subtype in the vertebrate peripheral nervous system. Neuron 34:577-588. CrossRef Medline

Gorelick DA, Watson W, Halpern ME (2008) Androgen receptor gene expression in the developing and adult zebrafish brain. Dev Dyn 237: 2987-2995. CrossRef Medline

Goto K, Kurashima R, Gokan H, Inoue N, Ito I, Watanabe S (2010) Leftright asymmetry defect in the hippocampal circuitry impairs spatial learning and working memory in iv mice. PLoS One 5:e15468. CrossRef Medline

Güntürkün O, Hellmann B, Melsbach G, Prior H (1998) Asymmetries of representation in the visual system of pigeons. Neuroreport 9:4127-4130. CrossRef Medline

Gutiérrez-Ibáñez C, Reddon AR, Kreuzer MB, Wylie DR, Hurd PL (2011) Variation in asymmetry of the habenular nucleus correlates with behavioural asymmetry in a cichlid fish. Behav Brain Res 221:189-196. CrossRef Medline

Jetti SK, Vendrell-Llopis N, Yaksi E (2014) Spontaneous activity governs olfactory representations in spatially organized habenular microcircuits. Curr Biol 24:434-439. CrossRef Medline

Kawakami R, Dobi A, Shigemoto R, Ito I (2008) Right isomerism of the brain in inversus viscerum mutant mice. PLoS One 3:e1945. CrossRef Medline

Kuan YS, Gamse JT, Schreiber AM, Halpern ME (2007a) Selective asymmetry in a conserved forebrain to midbrain projection. J Exp Zool B Mol Dev Evol 308:669-678. CrossRef Medline

Kuan YS, Yu HH, Moens CB, Halpern ME (2007b) Neuropilin asymmetry mediates a left-right difference in habenular connectivity. Development 134:857-865. CrossRef Medline

Lau BY, Mathur P, Gould GG, Guo S (2011) Identification of a brain center whose activity discriminates a choice behavior in zebrafish. Proc Natl Acad Sci U S A 108:2581-2586. CrossRef Medline

Lee A, Mathuru AS, Teh C, Kibat C, Korzh V, Penney TB, Jesuthasan S (2010) The habenula prevents helpless behavior in larval zebrafish. Curr Biol 20:2211-2216. CrossRef Medline

Lesch BJ, Gehrke AR, Bulyk ML, Bargmann CI (2009) Transcriptional regulation and stabilization of left-right neuronal identity in C. elegans. Genes Dev 23:345-358. CrossRef Medline

Levin ED, Bencan Z, Cerutti DT (2007) Anxiolytic effects of nicotine in zebrafish. Physiol Behav 90:54-58. CrossRef Medline

Liang JO, Etheridge A, Hantsoo L, Rubinstein AL, Nowak SJ, Izpisúa Belmonte JC, Halpern ME (2000) Asymmetric nodal signaling in the zebrafish diencephalon positions the pineal organ. Development 127: 5101-5112. Medline

Long S, Ahmad N, Rebagliati M (2003) The zebrafish nodal-related gene southpaw is required for visceral and diencephalic left-right asymmetry. Development 130:2303-2316. CrossRef Medline

Magno LD, Fontes A, Gonçalves BM, Gouveia A Jr (2015) Pharmacological study of the light/dark preference test in zebrafish (Danio rerio): Waterborne administration. Pharmacol Biochem Behav 135:169-176. CrossRef Medline

Manns M, Römling J (2012) The impact of asymmetrical light input on cerebral hemispheric specialization and interhemispheric cooperation. Nat Commun 3:696. CrossRef Medline

Maximino C, de Brito TM, da Silva Batista AW, Herculano AM, Morato S, Gouveia A Jr (2010) Measuring anxiety in zebrafish: a critical review. Behav Brain Res 214:157-171. CrossRef Medline

Okamoto H, Agetsuma M, Aizawa H (2012) Genetic dissection of the zebrafish habenula, a possible switching board for selection of behavioral strategy to cope with fear and anxiety. Dev Neurobiol 72:386-394. CrossRef Medline

Orman R, Stewart M (2007) Hemispheric differences in protein kinase C betaII levels in the rat amygdala: baseline asymmetry and lateralized changes associated with cue and context in a classical fear conditioning paradigm. Neuroscience 144:797-807. CrossRef Medline

Poole RJ, Hobert O (2006) Early embryonic programming of neuronal left/ right asymmetry in C. elegans. Curr Biol 16:2279-2292. CrossRef Medline

Rogers LJ (2008) Development and function of lateralization in the avian brain. Brain Res Bull 76:235-244. CrossRef Medline

Rosemberg DB, Rico EP, Mussulini BH, Piato AL, Calcagnotto ME, Bonan CD, Dias RD, Blaser RE, Souza DO, de Oliveira DL (2011) Differences in spatio-temporal behavior of zebrafish in the open tank paradigm after a short-period confinement into dark and bright environments. PLoS One 6:e19397. CrossRef Medline

Sackerman J, Donegan JJ, Cunningham CS, Nguyen NN, Lawless K, Long A, Benno RH, Gould GG (2010) Zebrafish behavior in novel environments: effects of acute exposure to anxiolytic compounds and choice of Danio rerio line. Int J Comp Psychol 23:43-61. Medline

Selye H (1976) Stress in health and disease. Boston: Butterworths.

Serra EL, Medalha CC, Mattioli R (1999) Natural preference of zebrafish (Danio rerio) for a dark environment. Braz J Med Biol Res 32:1551-1553. Medline

Shannon CE (1948) A mathematical theory of communication. Bell Syst Tech J 27:379-423. CrossRef

Signore IA, Guerrero N, Loosli F, Colombo A, Villalón A, Wittbrodt J, Concha ML (2009) Zebrafish and medaka: model organisms for a comparative developmental approach of brain asymmetry. Philos Trans R Soc Lond B Biol Sci 364:991-1003. CrossRef Medline

Sovrano VA, Andrew RJ (2006) Eye use during viewing a reflection: behavioural lateralisation in zebrafish larvae. Behav Brain Res 167:226-231. CrossRef Medline

Sovrano VA, Rainoldi C, Bisazza A, Vallortigara G (1999) Roots of brain specializations: preferential left-eye use during mirror-image inspection in six species of teleost fish. Behav Brain Res 106:175-180. CrossRef Medline

Suzuki H, Thiele TR, Faumont S, Ezcurra M, Lockery SR, Schafer WR (2008) Functional asymmetry in Caenorhabditis elegans taste neurons and its computational role in chemotaxis. Nature 454:114-117. CrossRef Medline

Valencia-Alfonso CE, Verhaal J, Güntürkün O (2009) Ascending and descending mechanisms of visual lateralization in pigeons. Philos Trans $\mathrm{R}$ Soc Lond B Biol Sci 364:955-963. CrossRef Medline

Walker C (1999) Haploid screens and gamma-ray mutagenesis. Methods Cell Biol 60:43-70. Medline

Wu Y, Kawakami R, Shinohara Y, Fukaya M, Sakimura K, Mishina M, Watanabe M, Ito I, Shigemoto R (2005) Target-cell-specific left-right asymmetry of NMDA receptor content in schaffer collateral synapses in epsilon1/NR2A knock-out mice. J Neurosci 25:9213-9226. CrossRef Medline

Yáñez J, Meissl H, Anadón R (1996) Central projections of the parapineal organ of the adult rainbow trout (Oncorhynchus mykiss). Cell Tissue Res 285:69-74. CrossRef Medline

Young EJ, Williams CL (2010) Valence dependent asymmetric release of norepinephrine in the basolateral amygdala. Behav Neurosci 124:633644. CrossRef Medline

Young EJ, Williams CL (2013) Differential activation of amygdala Arc expression by positive and negatively valenced emotional learning conditions. Front Behav Neurosci 7:191. CrossRef Medline 